\title{
Stereotactic radiosurgery for trigeminal neuralgia: a systematic review
}

\author{
International Stereotactic Radiosurgery Society practice guidelines
}

\author{
${ }^{*}$ Constantin Tuleasca, MD, ${ }^{1-4}$ Jean Régis, MD, ${ }^{11}$ Arjun Sahgal, MD, ${ }^{5}$ Antonio De Salles, MD, PhD, ${ }^{6}$ \\ Motohiro Hayashi, MD, ${ }^{7}$ Lijun Ma, PhD, ${ }^{8,9}$ Roberto Martínez-Álvarez, MD, ${ }^{10}$ lan Paddick, MSc, ${ }^{14}$ \\ Samuel Ryu, MD,12 Ben J. Slotman, MD, PhD, ${ }^{13}$ and Marc Levivier, MD, PhD ${ }^{10}$
}

\begin{abstract}
${ }^{1}$ Centre Hospitalier Universitaire Vaudois, Department of Clinical Neurosciences, Neurosurgery Service and Gamma Knife Center; ${ }^{2}$ University of Lausanne, Faculty of Biology and Medicine (FBM); ${ }^{3}$ Medical Image Analysis Laboratory, Centre Hospitalier Universitaire Vaudois; " Signal Processing Laboratory (LTS 5), Ecole Politechnique Fédérale de Lausanne (EPFL), Lausanne, Switzerland; ${ }^{5}$ Department of Radiation Oncology, University of Toronto, Sunnybrook Odette Cancer Centre, Toronto, ON, Canada; ${ }^{6}$ Department of Neurosurgery, University of California, Los Angeles, California; ${ }^{7}$ Department of Neurosurgery, Tokyo Women's Medical University, Tokyo; ${ }^{8}$ Department of Radiation Oncology, Kyoto University, Kyoto, Japan; ${ }^{9}$ Department of Radiation Oncology, University of California, San Francisco, California; ${ }^{10}$ Department of Neurosurgery, Ruber International Hospital, Madrid, Spain; "11Department of Functional and Stereotactic Neurosurgery and Gamma Knife Unit, Timone University Hospital, Aix-Marseille University, Marseille, France; ${ }^{12}$ Department of Radiation Oncology, Stony Brook University, Stony Brook, New York; ${ }^{13}$ Department of Radiation Oncology, VU University Medical Center, Amsterdam, The Netherlands; and ${ }^{14}$ Queen Square Radiosurgery Centre, National Hospital for Neurology and Neurosurgery, London, United Kingdom
\end{abstract}

OBJECTIVES The aims of this systematic review are to provide an objective summary of the published literature specific to the treatment of classical trigeminal neuralgia with stereotactic radiosurgery (RS) and to develop consensus guideline recommendations for the use of RS, as endorsed by the International Society of Stereotactic Radiosurgery (ISRS).

METHODS The authors performed a systematic review of the English-language literature from 1951 up to December 2015 using the Embase, PubMed, and MEDLINE databases. The following MeSH terms were used in a title and abstract screening: "radiosurgery" AND "trigeminal." Of the 585 initial results obtained, the authors performed a full text screening of 185 studies and ultimately found 65 eligible studies. Guideline recommendations were based on level of evidence and level of consensus, the latter predefined as at least $85 \%$ agreement among the ISRS guideline committee members.

RESULTS The results for 65 studies (6461 patients) are reported: 45 Gamma Knife RS (GKS) studies (5687 patients [88\%]), 11 linear accelerator (LINAC) RS studies (511 patients [8\%]), and 9 CyberKnife RS (CKR) studies (263 patients [4\%]). With the exception of one prospective study, all studies were retrospective.

The mean maximal doses were 71.1-90.1 Gy (prescribed at the 100\% isodose line) for GKS, 83.3 Gy for LINAC, and 64.3-80.5 Gy for CKR (the latter two prescribed at the $80 \%$ or $90 \%$ isodose lines, respectively). The ranges of maximal doses were as follows: 60-97 Gy for GKS, 50-90 Gy for LINAC, and 66-90 Gy for CKR.

Actuarial initial freedom from pain (FFP) without medication ranged from $28.6 \%$ to $100 \%$ (mean $53.1 \%$, median $52.1 \%$ ) for GKS, from $17.3 \%$ to $76 \%$ (mean $49.3 \%$, median $43.2 \%$ ) for LINAC, and from $40 \%$ to $72 \%$ (mean $56.3 \%$, median $58 \%$ ) for CKR. Specific to hypesthesia, the crude rates (all Barrow Neurological Institute Pain Intensity Scale scores included) ranged from $0 \%$ to $68.8 \%$ (mean $21.7 \%$, median 19\%) for GKS, from $11.4 \%$ to $49.7 \%$ (mean $27.6 \%$, median $28.5 \%$ ) for LINAC, and from $11.8 \%$ to $51.2 \%$ (mean $29.1 \%$, median 18.7\%) for CKR. Other complications included dysesthesias, paresthesias, dry eye, deafferentation pain, and keratitis. Hypesthesia and paresthesia occurred as complications only

\footnotetext{
ABBREVIATIONS BMC = balloon microcompression; BNI = Barrow Neurological Institute; $C K R=$ CyberKnife radiosurgery; DVH $=$ dose-volume histogram; FFP $=$ freedom from pain; GKS = Gamma Knife surgery; HSRT = hypofractionated stereotactic radiotherapy; ISRS = International Society of Stereotactic Radiosurgery; LINAC = linear accelerator; MVD = microvascular decompression; $\mathrm{QOL}=$ quality of life; RCT = randomized controlled trial; REZ = root entry zone; RFT = radiofrequency thermocoagulation; RS = radiosurgery; SCA = superior cerebellar artery; TN = trigeminal neuralgia; TTPR = time to pain relief.

SUBMITTED March 2, 2017. ACCEPTED September 11, 2017.

INCLUDE WHEN CITING Published online April 27, 2018; DOI: 10.3171/2017.9.JNS17545.

* C.T. and J.R. contributed equally to this study.
} 
when the anterior retrogasserian portion of the trigeminal nerve was targeted, whereas the other listed complications occurred when the root entry zone was targeted. Recurrence rates ranged from $0 \%$ to $52.2 \%$ (mean $24.6 \%$, median $23 \%$ ) for GKS, from $19 \%$ to $63 \%$ (mean $32.2 \%$, median $29 \%$ ) for LINAC, and from $15.8 \%$ to $33 \%$ (mean $25.8 \%$, median $27.2 \%$ ) for CKR. Two GKS series reported $30 \%$ and $45.3 \%$ of patients who were pain free without medication at 10 years.

CONCLUSIONS The literature is limited in its level of evidence, with only one comparative randomized trial ( 1 vs 2 isocenters) reported to date. At present, one can conclude that RS is a safe and effective therapy for drug-resistant trigeminal neuralgia. A number of consensus statements have been made and endorsed by the ISRS.

https://thejns.org/doi/abs/10.3171/2017.9.JNS17545

KEYWORDS trigeminal neuralgia; systematic review; functional neurosurgery; stereotactic radiosurgery; pain

$\mathrm{T}$ Rigeminal neuralgia (TN), referred to as "tic doloureux" by the French neurosurgeon André, ${ }^{5}$ is a severe, unilateral, lancinating, and electric-like facial pain. It remains the most common neuralgia but with a low global incidence of 4-5 cases per 100,000 persons. Diagnosis of this condition is made mainly on a clinical basis given the classic signs and symptoms of paroxysmal attacks with an abrupt onset, a duration of seconds to 2 minutes, periods of spontaneous remission, the presence of "trigger zones," no objective neurological deficit, no other identified causes of facial pain, the most common distribution along the second or third division of the trigeminal verve, and an initial response to carbamazepine. ${ }^{45}$

The leading pathophysiological hypothesis specific to idiopathic TN describes demyelination of trigeminal sensory fibers within the proximal nerve root. ${ }^{79}$ According to the preliminary findings of Walter Dandy, ${ }^{23}$ which were confirmed decades later, most patients $(80 \%-90 \%)$ present with an overlying blood vessel causing neurovascular compression at the root entry zone (REZ). ${ }^{11}$ The vessel most frequently involved is the superior cerebellar artery (SCA), but veins can also contribute to this phenomenon. ${ }^{11}$

Classification of TN as established by the International Headache Society ${ }^{45}$ includes classical and symptomatic. "Classical TN" refers to all cases without an established etiology (idiopathic), including those with potential vascular compression. Symptomatic TN is often caused by a tumor, multiple sclerosis, or skull-base structural abnormalities. ${ }^{45}$ Patients with a suspected diagnosis of TN should undergo brain MRI to better visualize the trigeminal nerve and the eventual offending vessel but also to exclude secondary cases of TN in the context of a tumor, demyelinating disease, vascular malformations, and so forth.

The first therapeutic line is pharmacological with carbamazepine. Initial effectiveness has been reported in nearly $90 \%$ of patients $\mathrm{s}^{52}$ and is the only antiepileptic drug shown in randomized controlled trials (RCTs) to reduce both the intensity and frequency of attacks. ${ }^{139}$ Nevertheless, due to the induction of hepatic enzymes, which metabolize the drug, its efficacy can decrease or even decline completely after a period of stability at a given dose, and higher doses can become necessary. Additionally, patients can develop a large spectrum of side effects, some interfering strongly with quality of life (QOL).

The second therapeutic line is surgical and is reserved for patients with medically intractable pain or those who present with side effects related to medication. The 3 main surgical techniques include microvascular decompression
(MVD), percutaneous procedures (balloon microcompression [BMC], glycerol injection, radiofrequency thermocoagulation [RFT]), and external beam stereotactic radiosurgery (RS).

Microvascular decompression, pioneered by Peter Jannetta, is considered the reference technique as it addresses the underlying cause, that is, neurovascular compression..$^{50}$ Although the procedure offers rapid improvement, probably because of the immediate setback of the underlying distortion and compression of demyelinated axons, major complications of the surgery can include death, brainstem infarction, ipsilateral hearing loss, CSF leakage, and so forth. ${ }^{11,50}$ What is less clear is the extent to which normal remyelination occurs over the long term to contribute to the resolution of the pathological axonal arrangement. ${ }^{79}$ Percutaneous procedures are also effective, considered to be ablative techniques and mechanistically based on physical (BMC), thermic (RFT), or chemical (glycerol injection) action at the level of the gasserian ganglion. There are no RCTs comparing the outcomes of these types of interventions, but all are considered ablative procedures given their high risk of producing dysesthesias, corneal keratitis, or severe facial numbness.

In 1951 the concept of RS was introduced by the Swedish neurosurgeon Lars Leksell, who treated a TN patient using a prototype guiding device linked to a dental x-ray machine. Essentially a "stereotactic gangliotomy" 69 was performed, similar to the concept of a percutaneous technique. As external beam technology and neuroimaging evolved, technologies such as the Gamma Knife, linear accelerator (LINAC), and CyberKnife RS (CKR) developed. The main principle of RS, regardless of the technique, is to target the trigeminal nerve with high precision, in a single session, based on high-resolution MRI and CT studies. With the evolution of neuroimaging came refinement in the technique and the target. Several large Gamma Knife surgery (GKS) series have already advocated for the safety and efficacy of RS, in particular, by reporting longterm and very-long-term results. ${ }^{63,110,114,115,144}$ Additionally, a small number of studies have reported outcomes for the other RS techniques, including the LINAC and CKR, though with a more limited number of patients and followup periods. . $^{1,12,31,102,119,124,125,129,138}$

The aims of this systematic review are to provide an objective summary of the published literature specific to the treatment of TN with RS and to develop consensus guideline recommendations for the use of RS, as endorsed by the International Society of Stereotactic Radiosurgery (ISRS). 
Title and abstract screening, $n=585$

Articles published from 1951, Dec week 4,

2015

Three electronic databases:

Pubmed, EMBASE, The Cochrane central

Strategy: "radiosurgery " and " trigeminal "

Where: title and/or abstract
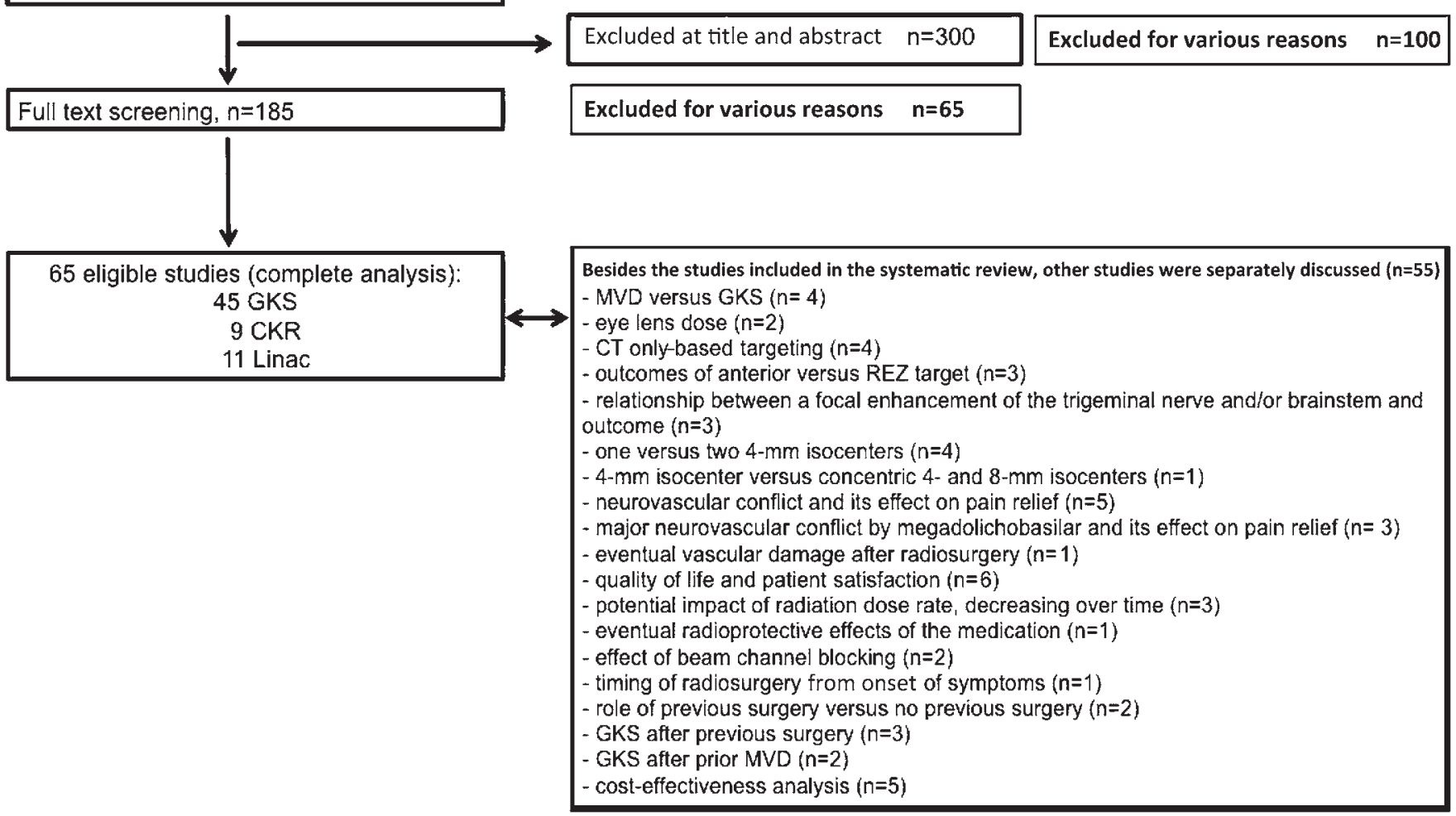

FIG. 1. Flow chart to final number of eligible studies.

\section{Methods}

\section{Search Method}

A systematic review of the English-language literature from 1951-December 2015 was performed using the MEDLINE, Embase, and PubMed databases. The following search terms were used in a screening of titles and/or abstracts: "radiosurgery" AND "trigeminal."

\section{Inclusion Criteria and Identified Studies}

Inclusion criteria were as follows: articles (prospective and retrospective studies) written in the English language and reporting on outcomes specific to external beam radiosurgical treatments of classical idiopathic TN, the first RS treatment, MRI-based targeting (CT-based targeting reported separately to exclude potential bias), and clear outcomes obtained using validated instruments. Conversely, exclusion criteria were studies that did not report specific outcomes for idiopathic $\mathrm{TN}$ and those reporting on repeat $\mathrm{RS}$ or RS in the treatment of TN associated with multiple sclerosis or other secondary causes. Duplicate studies were defined as those including outcomes on a previously reported population; however, if the study included additional patients and more follow-up data that were sepa- rately described, that new information was included. Five hundred eighty-five studies were initially identified (Fig. 1), and 300 were excluded at the title and abstract screening because they did not meet inclusion criteria. From the remaining 285 studies, 100 were excluded for various reasons. One hundred eighty-five studies were subjected to a full-text review, 65 of which did not meet inclusion criteria, leaving 120 studies for subsequent analysis. Sixtyfive of these 120 studies were considered relevant to the present review, and the remaining 55 papers were also reviewed and are discussed separately as they deal with specific aspects that need to be discussed in the context of TN (Fig. 1).

\section{Reporting Results}

Results are reported for the 65 studies (6461 patients): 45 GKS studies (5687 patients [88\%]), ${ }^{8,9,17,21,24,25,27,28,43,44,49,53,}$ $57,59,61-63,66,67,74,76,77,80,82,83,85,89,90,98,100,103,106,111,112,114,117,118,120,111,132$, 146,137,144,145,149 11 LINAC RS studies (511 patients [8\%]), ${ }^{18,19}$, 26,39,42,64,108,116,124,125,146 and 9 CKR RS studies (263 patients [4\%]) $1,31,65,72,102,119,126,129,138$ (Table 1). With the exception of 1 prospective study by Régis et al., ${ }^{112}$ all other studies were retrospective. 
TABLE 1. Summary of studies included in this systematic review

\begin{tabular}{|c|c|c|c|c|c|c|c|}
\hline Authors \& Year & $\begin{array}{l}\text { No. of } \\
\text { Cases }\end{array}$ & $\begin{array}{c}\text { Mean Age } \\
\text { in Yrs (range) }\end{array}$ & $\begin{array}{l}\text { Mean or Median } \\
\text { FU (mos) }\end{array}$ & $\begin{array}{l}\text { FU Range } \\
\text { (mos) }\end{array}$ & $\begin{array}{l}\text { Mean or Median } \\
\text { Dose in Gy }\end{array}$ & $\begin{array}{l}\text { Maximal } \\
\text { Dose in Gy }\end{array}$ & $\begin{array}{l}\text { Target in Relation } \\
\text { to REZ (mm) }\end{array}$ \\
\hline \multicolumn{8}{|l|}{ GKS studies } \\
\hline Régis et al., 1995 & 20 & $75(59-83)$ & $11 \dagger$ & $3-18$ & $84^{*} / 90 \dagger$ & $70-90$ & $7-8$ \\
\hline Kondziolka et al., $1996^{59}$ & 51 & $64(21-89)$ & $9.6^{*}$ & $2-29$ & - & $60-90$ & $2-4$ \\
\hline Kondziolka et al., $19966^{61}$ & 50 & - & $19 \dagger$ & $11-36$ & $71.1^{*}$ & $60-90$ & - \\
\hline Young et al., 1997 & 51 & - & $16.3^{*}$ & $6-36$ & - & - & 0 \\
\hline Kondziolka et al., 1998 & 106 & $67(32-92)$ & $18 \dagger$ & $6-48$ & $75.9 * / 80 \dagger$ & $70-90$ & $2-4$ \\
\hline Kannan et al., 1999 & 6 & $56(42-79)$ & - & $5-16$ & $75.7 * / 80 \dagger$ & $70-80$ & $2-4$ \\
\hline Chang et al., 2000 & 15 & $63.8(38.7-82.2)$ & $7.1^{*}$ & $3.9-23.7$ & $76.3^{*}$ & $70-80$ & - \\
\hline Rogers et al., 2000 & 54 & $67(43-89)$ & $12 \dagger$ & $3-28$ & $70 \dagger$ & $70-80$ & - \\
\hline Maesawa et al., 2001 & 220 & $70(26-92)$ & $22 \dagger$ & $1-78$ & $80 \dagger$ & $60-90$ & $2-4$ \\
\hline Zheng et al., 2001 & 80 & $67(32-92)$ & $23.7^{*}$ & $12-43$ & $75.6^{*}$ & $70-90$ & $4-6$ \\
\hline Matsuda et al., 2002 & 41 & - & $13^{*}$ & $3-36$ & $80 \dagger$ & 80 & 0 \\
\hline Pollock et al., 2002 & 117 & 67.8 & $26 \dagger$ & $1-48$ & $82.6^{*}$ & $70-90$ & - \\
\hline Petit et al., 2003 & 112 & $64(24-95)$ & $30 \dagger$ & $8-66$ & - & $70-80$ & $2-4$ \\
\hline Shaya et al., 2004 & 40 & $64.3(39-82)$ & $14 \dagger$ & $3-31$ & $80^{*}$ & $70-90$ & $2-4$ \\
\hline Massager et al., 2004 & 47 & $69(35-86)$ & $16^{*}$ & $6-42$ & $90 \dagger$ & 90 & $7-8$ \\
\hline Cheuk et al., 2004 & 112 & $62.02(24-96)$ & - & - & $75 \dagger$ & $60-80$ & $2-4$ \\
\hline Drzymala et al., 2005 & 73 & $69(34-100)$ & $13.7 \dagger$ & $1.3-44.7$ & $87 \dagger$ & $76-98$ & 0 \\
\hline McNatt et al., 2005 & 49 & $68(38-87)$ & $44^{*}$ & $12-70$ & $80^{*}$ & 80 & 0 \\
\hline Sheehan et al., 2005 & 136 & $68(22-90)$ & $19 \dagger$ & $2-96$ & $80 \dagger$ & $50-90$ & $2-4$ \\
\hline Tawk et al., 2005 & 38 & $70(29-88)$ & $24 \dagger$ & $6-27$ & $80.5^{\star} / 80 \dagger$ & $70-90$ & 0 \\
\hline Urgosik et al., 2005 & 107 & $75(45-91)$ & $60 \dagger$ & $12-96$ & $76.6 * / 80 \dagger$ & $70-80$ & 0 \\
\hline Régis et al., 2006 & 100 & $67.5(29-90)$ & - & - & $85 \dagger$ & $70-90$ & 7.8 \\
\hline Longhi et al., 2007 & 170 & $63.4(23-89)$ & $37.4^{*}$ & $6-144$ & $85^{*}$ & $75-95$ & $2-5$ \\
\hline Little et al., 2008 & 185 & $69(57-81)$ & $75.6^{*}$ & $48-126$ & $80 \dagger$ & $70-90$ & 0 \\
\hline Huang et al., $2008^{49}$ & 89 & $63.2(34-85)$ & $68^{*}$ & $32-104$ & $78.8^{*}$ & $60-90$ & 0 \\
\hline Dellaretti et al., 2008 & 76 & $64(27-83)$ & $20.3^{*}$ & $6-42$ & $85.1^{*}$ & $75-90$ & $7-8$ \\
\hline Azar et al., 2009 & 30 & $55(31-80)$ & - & - & $90.1 * / 90 \dagger$ & $85-95$ & $2-4$ \\
\hline Han et al., 2009 & 62 & $61(50-73)$ & $58^{*}$ & $16-107$ & $79.7^{*}$ & $75-80$ & $2-4$ \\
\hline Dhople et al., 2009 & 112 & $64(24-96)$ & $67.2 \dagger$ & $13-115$ & $75 \dagger$ & $70-80$ & 0 \\
\hline Riesenburger et al., 2010 & 53 & $65.8(38-94)$ & $48^{*}$ & $36-66$ & $80.6 * / 80 \dagger$ & $75-90$ & $0(72 \%)$ \& Meckel's cave $(28 \%)$ \\
\hline Verheul et al., 2010 & 450 & 65 (27-91) & $28 \dagger$ & $3-85$ & $80^{*}$ & 80 & 0 \\
\hline Kondziolka et al., 2010 & 503 & $72(26-95)$ & $24 \dagger$ & $3-156$ & $80 \dagger$ & $60-90$ & $2-4$ \\
\hline Park et al., 2011100 & 62 & $62.7(51.4-74)$ & $76.4 \dagger$ & $12-161$ & $82.4^{*} / 85 \dagger$ & $68-90$ & 0 \\
\hline Loescher et al., 2012 & 72 & 65.6 & - & - & $80^{*}$ & 80 & 0 \\
\hline Hayashi et al., 2011 & 130 & $68(31-88)$ & $38^{*}$ & $24-66$ & - & - & $7-8$ \\
\hline Park \& Hwang, 2011 & 17 & $62.7(41-82)$ & $43.8^{*}$ & $36-59$ & $80^{*}$ & $80-90$ & $2-4$ \\
\hline Lee et al., 2012 & 40 & $61.5(25-84)$ & $92^{*}$ & $60-144$ & $77.1^{*}$ & $65.2-83.6$ & 0 \\
\hline Marshall et al., 2012 & 448 & $67(22-92)$ & $20.9^{*}$ & $3-86$ & $88 * / 90 \dagger$ & $80-97$ & $2-4$ \\
\hline Elaimy et al., 2012 & 108 & $67(22-94)$ & $15 \dagger$ & - & $86 \dagger$ & $70-90$ & 0 \\
\hline Young et al., 2013 & 315 & $70.8(52.9-84.1)$ & $68.9^{*}$ & $27.1-110.7$ & $90 \dagger$ & 90 & $2-4$ \\
\hline Lee et al., 2013 & 91 & - & - & $24-90$ & $88^{*}$ & $75-90$ & $7-8$ \\
\hline Aykol et al., 2014 & 93 & $57.06(18-87$ & $57.1^{*}$ & $12-84$ & $80.38^{*}$ & $70-90$ & 0 \\
\hline Karam et al., 2014 & 36 & $71(29-97)$ & $36 \dagger$ & - & $90 \dagger$ & $80-90$ & 0 \\
\hline Lucas et al., 2014 & 446 & $67.5(56.6-75.8)$ & $21.2 \dagger$ & $9.7-43$ & $88.06 * / 90 \dagger$ & $80-97$ & Retrogasserian \\
\hline Régis et al., $2016^{114}$ & 497 & $68.3(28.1-93.2)$ & $43.8 \dagger$ & $12-174.4$ & $85 \dagger$ & $70-90$ & 7.6 \\
\hline \multicolumn{8}{|l|}{ CKR studies } \\
\hline Romanelli et al., 2003 & 10 & - & - & - & $64.3^{*}$ & $66-70$ & 3 \\
\hline
\end{tabular}




\section{» CONTINUED FROM PAGE 736}

TABLE 1. Summary of studies included in this systematic review

\begin{tabular}{|c|c|c|c|c|c|c|c|}
\hline Authors \& Year & $\begin{array}{l}\text { No. of } \\
\text { Cases }\end{array}$ & $\begin{array}{c}\text { Mean Age } \\
\text { in Yrs (range) }\end{array}$ & $\begin{array}{l}\text { Mean or Median } \\
\text { FU (mos) }\end{array}$ & $\begin{array}{l}\text { FU Range } \\
\text { (mos) }\end{array}$ & $\begin{array}{c}\text { Mean or Median } \\
\text { Dose in Gy }\end{array}$ & $\begin{array}{c}\text { Maximal } \\
\text { Dose in Gy }\end{array}$ & $\begin{array}{c}\text { Target in Relation } \\
\text { to REZ }(\mathrm{mm})\end{array}$ \\
\hline \multicolumn{8}{|l|}{ CKR studies (continued) } \\
\hline Lim et al., 2005 & 41 & 68 & $11^{*}$ & $6-15$ & $70.7^{*}$ & - & $2-3$ \\
\hline Villavicencio et al., 2008 & 95 & 69.8 & $22 \dagger$ & $12-46$ & $78 \dagger$ & $70-85.4$ & $2-3$ \\
\hline Fariselli et al., 2009 & 33 & 74 & $23 \dagger$ & $9-37$ & - & - & $2-3$ \\
\hline Adler et al., 2009 & 46 & 78 & $10.5^{*}$ & $6-29$ & $73.5^{*}$ & - & $2-3$ \\
\hline Lazzara et al., 2013 & 17 & 69.4 & $11.8^{*}$ & $1-27$ & $73.06^{*}$ & $72.91-73.73$ & $2-3$ \\
\hline Tang et al., 2011 & 16 & 67.8 & $20.4^{*}$ & $6-32$ & $80.5^{*}$ & $75-86.5$ & 3 \\
\hline Peddada et al., 2011 & 1 & 74 & - & - & - & - & $2-3$ \\
\hline Soboleva et al., 2012 & 4 & 63 & $8^{*}$ & - & - & $70-90$ & - \\
\hline \multicolumn{8}{|l|}{ LINAC studies } \\
\hline Goss et al., 2003 & 25 & $65(50-84)$ & $18^{*}$ & $8-52$ & $90 \dagger$ & 90 & 0 \\
\hline Smith et al., 2003 & 60 & 66.1 & $23 \dagger$ & $2-70$ & $83.3^{*}$ & $70-90$ & 0 \\
\hline Frighetto et al., 2004 & 22 & - & $21.2^{*}$ & $8-52$ & $90 \dagger$ & $75-90$ & 0 \\
\hline Kubicek et al., 2004 & 20 & $58(40-81)$ & $56.5^{*}$ & - & - & $82.3-100$ & 0 \\
\hline Chen et al., 2004 & 44 & 65 & $15 \dagger$ & - & - & 90 & 0 \\
\hline Richards et al., 2005 & 28 & $74(44-88)$ & $12 \dagger$ & $1-40$ & $80 \dagger$ & 80 & 0 \\
\hline Pusztaszeri et al., 2007 & 17 & $71(48-77)$ & $12 \dagger$ & $1-60$ & - & $50-56$ & 0 \\
\hline Zahra et al., 2009 & 20 & - & $14.2 \dagger$ & - & - & 90 & 0 \\
\hline Chen et al., 2010 & 44 & 65 (32.2-90.5) & $15 \dagger$ & - & $90 \dagger$ & 90 & 0 \\
\hline Dos Santos et al., 2011 & 52 & - & $26.6 \dagger$ & $6.3-99.9$ & - & $50-80$ & Gasserian/cisternal \\
\hline Smith et al., 2011 & 179 & $74(32-90)$ & $26.6 \dagger$ & $5-89$ & - & $70-90$ & 0 \\
\hline
\end{tabular}

In addition to those studies selected for the systematic review, we separately discuss trials that considered MVD versus RS (4 studies); ${ }^{73,92,94,107}$ eye lens dose (2); ${ }^{70,81} \mathrm{CT}$ only-based targeting (4); ;,71,96,140 anterior versus REZ target (3); ${ }^{88,99,141}$ the relationship between focal enhancement of the trigeminal nerve and/or brainstem and outcome (3); ;2,38,40 one versus two 4-mm isocenters (4); ;,26,32,106 one 4-mm isocenter versus concentric 4- and 8-mm isocenters (1) $; 54$ the neurovascular conflict and its effect on pain relief (5): ${ }^{14,30,85,120,122}$ major neurovascular conflict by the megadolichobasilar artery (3); $97,127,135$ eventual vascular damage after RS (1); $;{ }^{78}$ QOL and patient satisfaction (6);9,51,95, 103,112,115 potential impact of radiation dose rate (3);, $; 10,68$ eventual radioprotective effects of medication (1); ${ }^{33}$ effect of beam channel blocking, with a longer irradiated nerve and integral dose (2): 86,87 timing of RS from the onset of symptoms (1):91 previous surgery versus no previous surgery (2); ${ }^{34,35}$ GKS after previous surgery (3); ${ }^{49,57,77}$ GKS after prior MVD (2): $;^{75,133}$ and cost-effectiveness analysis (5). $37,46,105,123,131$

\section{Outcome Measures}

Most of the studies reported outcomes using the Barrow Neurological Institute (BNI) Pain Intensity Scale or a variation: I, complete pain relief without medication; II, occasional pain not requiring medication; III, some pain but adequately controlled with medications; IV, some pain inadequately controlled with medication; V, continued severe pain or no pain relief. ${ }^{118}$ Other studies used the classification proposed by Eller et al. ${ }^{29}$ which refers to idiopathic TN types 1 and 2 . Trigeminal neuralgia type 1 (TN1) is described as typically sharp, shooting, electrical shock-like, episodic pain that is present more than $50 \%$ of the time but with pain-free intervals between attacks; TN2 is described as an aching, throbbing, or burning pain that is present more than $50 \%$ of the time but is constant in nature (constant background pain being the most significant attribute). The published data are confusing in some instances because some studies include patients with atypical pain and do not always describe it separately.

\section{Recommendations Based on Agreement}

Recommendations have been summarized based on the level of evidence (Table 2). Recommended statements were evaluated through a modified Delphi approach. The 2014 ISRS Board (all authors on these guidelines) independently rated their agreement with each recommendation on a 5-point scale (strongly agree, agree, disagree, strongly disagree, or uncertain). A prespecified threshold of $85 \%$ or more agreement (agree or strongly agree responses) represented consensus. 
TABLE 2. Levels of evidence

\begin{tabular}{|c|c|}
\hline Level & Description \\
\hline I & $\begin{array}{l}\text { Evidence from } 1 \text { or more well-designed, randomized con- } \\
\text { trolled clinical trials, including overviews of such trials }\end{array}$ \\
\hline II & $\begin{array}{l}\text { Evidence from } 1 \text { or more well-designed comparative clinical } \\
\text { studies such as nonrandomized cohort studies, case- } \\
\text { control studies, and other comparable studies, including } \\
\text { less well-designed RCTs }\end{array}$ \\
\hline III & $\begin{array}{l}\text { Evidence from case series, comparative studies with histori- } \\
\text { cal controls, case reports, and expert opinion, as well as } \\
\text { significantly flawed RCTs }\end{array}$ \\
\hline
\end{tabular}

\section{Data Analysis}

For all nonrandomized studies, the generic inverse variance method and fixed effects model in Review Manager (RevMan, version 5.3, Copenhagen: The Nordic Cochrane Centre, The Cochrane Collaboration, 2014) were used to pool data. The outcome measures used the log hazard ratio (lnHR) and its variance, which were estimated using the hazard ratio meta-analysis toolbox. ${ }^{101}$

\section{Results}

\section{Follow-Up Periods}

The mean and median follow-up periods for GKS ranged from 7.1 to 92 months and from 6.7 to 76 months (range 0-174.4 months), respectively. For LINAC studies, they ranged from 18 to 56.5 months and from 12 to 26.6 months (range 1-99.9 months), respectively. For CKR studies, they ranged from 8 to 20.4 months and from 22 to 23 months (range 1-46 months), respectively.

\section{Radiosurgical Procedure: Mask or Frame Application and MRI Sequences}

Gamma Knife surgery uses stereotactic head frame immobilization and is considered the gold standard of RS for TN. ${ }^{113}$ After application of a local anesthetic, the Leksell stereotactic G frame (Elekta Instruments AB) is fixed on the patient's head so that the frame is parallel to the intracisternal part of the fifth cranial nerve, which can be accomplished by corresponding the plane of the frame base to the orbitomeatal plane. The projection of the trigeminal incisura of the petrous bone can be localized 1.5 $\mathrm{cm}$ anterior and $1.5 \mathrm{~cm}$ superior to the external auditory meatus. The trigeminal incisura is positioned close to the center of the $\mathrm{y}$-axis with appropriate adjustment in the zaxis.

Linear accelerator-based systems utilize stereotactic head frame immobilization or a facial mask with image guidance. In the vast majority of studies, a spherical dose distribution is delivered by 5-7 noncoplanar arcs through a circular collimator $(4-5 \mathrm{~mm}){ }^{41}$

The CKR treatment requires facial mask immobilization, and the radiation dose is delivered by an X-band LINAC mounted on a robotic arm and guided by real-time imaging-assisted target tracking. The CKR dose plan is prepared using a CT scan that is fused with an MR image for delineation of the nerve and brainstem. A 5- or 7.5-mm cone and trigeminal node set, which has a shorter sourceto-axis distance, is used..$^{31}$

With respect to imaging for treatment planning, T1weighted with and/or without the injection of gadolinium and T2 constructive interference in steady state (CISS)/ fast imaging employing steady state acquisition (FIESTA) sequences are used. . $^{31,41,63,113,114}$ In certain GKS centers, a CT scan supplements the neuroradiological examination. Targeting based solely on CT is discussed separately (see Discussion, Targeting the Trigeminal Nerve Based Only on CT Images).

\section{Radiosurgical Procedure: Dose Selection and Target Dose Selection}

The mean maximal doses ranged from 71.1 to $90.1 \mathrm{~Gy}$ (prescribed at the $100 \%$ isodose line) for the GKS studies, from 70 to 90 Gy for LINAC studies, and from 64.3 to 80.5 Gy for CKR studies (the latter two prescribed at the $80 \%$ or $90 \%$ isodose lines, respectively; Table 1). The ranges of maximal doses were as follows: 60-97 Gy (large majority 60-90 Gy, more being rather exceptional) for GKS, 50-90 Gy for LINAC, and 66-90 Gy for CKR.

\section{Target Selection}

The anterior cisternal target has been used by Rand et al., ${ }^{109}$ Régis et al., ${ }^{112,114,115,134}$ Dellaretti et al., ${ }^{24}$ Lucas et al., ${ }^{80}$ and Massager et al ${ }^{85}$ Otherwise, the REZ has been the most consistent target (Table 1 and Fig. 2). ${ }^{63,106}$

\section{Outcomes}

\section{Pain Relief Response and Time Points}

The freedom from pain (FFP) response with or without medication adjustment is summarized as follows (mean and median [range]): GKS, 84.8\% and 85.6\% (66.6\%$100 \%)$; LINAC, $87.3 \%$ and $88.5 \%$ (75\%-100\%); and CKR, $79.3 \%$ and $79 \%$ (50\%-100\%; Table 3). The difference in the FFP response between GKS and LINAC-based RS treatment was not statistically significant $(p=0.4,2$-sample $\mathrm{t}$-test), with a difference of $-2.5 \%$ between the means. Neither was there a statistically significant difference between GKS and CKR ( $p=0.42,2$-sample t-test), with a difference of $5.4 \%$ between the means.

The FFP response without medication was as follows (mean and median [range]: GKS, $53.1 \%$ and $52.1 \%$ (28.6\%-100\%); LINAC, $49.3 \%$ and $43.2 \%$ (17.3\%-76\%); and CKR, $56.3 \%$ and $58 \%(40 \%-72 \%)$. The difference in the FFP response between GKS and LINAC was not statistically significant $(\mathrm{p}=0.54,2$-sample t-test), with a difference of $3.8 \%$ between the means. Neither was there a statistically significant difference between GKS and CKR $(p=0.64,2$-sample t-test), with a difference of $-3.1 \%$ between the means.

The times to pain relief (TTPRs) were as follows: the mean and median ranged from 15 to 78 days and from 10 to 90 days, respectively, for GKS; and from 28 to 81 days and from 8.5 to 60 days, respectively, for LINAC. The mean and median were not reported for the CKR studies.

The range intervals for TTPR varied from 0 to 480 days (all studies included), with most authors of the stud- 

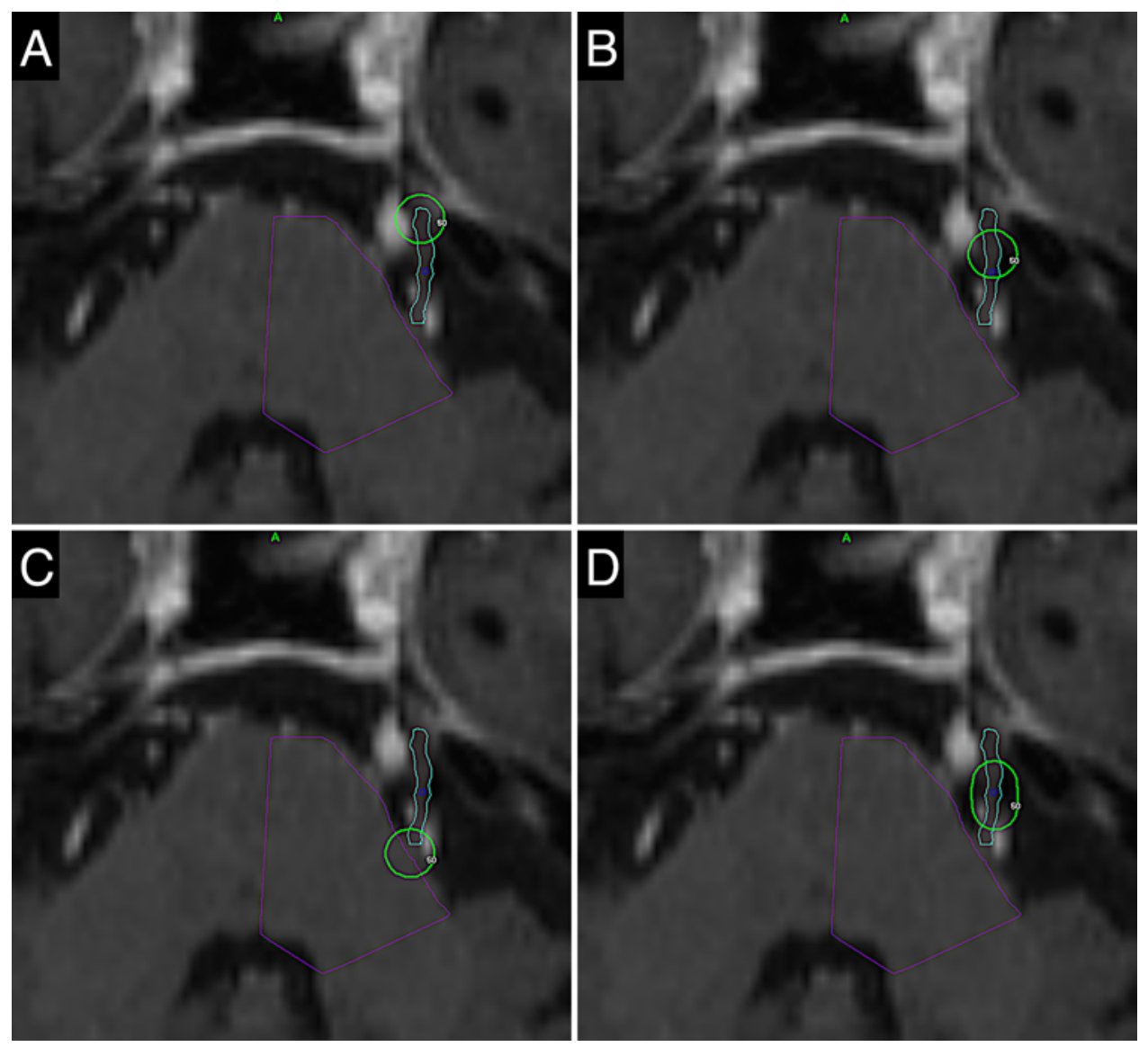

FIG. 2. Examples of different types of targeting (simulation), including the plexus triangularis (A), retrogasserian portion (far anterior cisternal, B), REZ with 30\% isodose line overlapping the brainstem (C), and the use of 2 isocenters (D). Purple line indicates the brainstem area (for further DVH measurements; light blue line, the trigeminal nerve; green line, the $50 \%$ isodose line; and dark blue area, approximate middle point of trigeminal nerve, in the retrogasserian area. Figure is available in color online only.

ies agreeing that the maximum interval for pain relief can be considered 180 days after radiosurgical treatment.

\section{Hypesthesia and/or Other Complications and Time Points}

Hypesthesia onset (all BNI scores included, crude rates) among the studies was as follows (mean and median [range]): for GKS, $21.7 \%$ and $19 \%(0 \%-68.8 \%)$; for LINAC, $27.6 \%$ and $28.5 \%(11.4 \%-49.7 \%)$; and for CKR, $29.1 \%$ and $18.7 \%$ (11.8\%-51.2\%; Table 4). The difference in the onset of hypesthesia between GKS and LINAC studies was not statistically significant $(\mathrm{p}=0.22$, 2-sample t-test), with a difference of $-5.89 \%$ between the means. However, the follow-up for LINAC studies was more limited in time; therefore, the incidence of hypesthesia was probably underestimated.

The difference in the onset of hypesthesia between GKS and CKR studies was not statistically significant (p $=0.43,2$-sample t-test), with a difference of $-7.46 \%$ s between the means. However, the follow-up period for the CKR studies was more limited in time, with an eventual underestimation of this reported outcome. Furthermore, the technical nuances of each technique preclude a fair comparison between the two.

The mean time to hypesthesia onset in the GKS group ranged from 6 to 36 months, and the time varied from 1 to 94 months. Time to hypesthesia onset was not reported in the CKR and LINAC studies.

Bothersome or very bothersome hypesthesia onset (BNI scores III and IV) was reported as follows: for GKS studies, it ranged from $0 \%$ to $17.3 \%$, with a mean of $3.1 \%$ and a median of $0 \%$; for LINAC, one study reported $13.6 \%$; and for CKR studies, it ranged from $5.9 \%$ to $12 \%$, with a mean of $9.3 \%$ and a median of $10 \%$. The difference between the GKS and CKR studies was statistically significant for BNI scores III and IV ( $p=0.05,2$-sample t-test), with a difference of $-6.19 \%$ between the means.

Data for complications other than hypesthesia are also presented in Table 4.

\section{Recurrence Rates and Time Points}

The mean and median recurrence rates for the GKS studies were $24.6 \%$ and $23 \%$, respectively (range $0 \%-52.2 \%$; Table 4). For LINAC-based studies, the mean and median rates were $32.2 \%$ and $29 \%$, respectively (range 19\%-63\%). For CKR-based studies, the mean and median rates were $25.8 \%$ and $27.2 \%$, respectively (range $15.8 \%-33 \%$ ).

The difference between the GKS and LINAC studies was statistically significant for BNI scores III and IV ( $p=$ 
TABLE 3. Freedom from pain response and interval to the response

\begin{tabular}{|c|c|c|c|c|}
\hline Authors \& Year & FFP w/ Medication (\%) & FFP w/o Medication (\%) & Mean \&/or Median TTPR (days) & TTPR Range (days) \\
\hline \multicolumn{5}{|l|}{ GKS studies } \\
\hline Régis et al., 1995 & 80.00 & 80.00 & $20.5^{\star} / 25.5 \dagger$ & $1-30$ \\
\hline Kondziolka et al., $1996^{59}$ & 86.00 & - & - & - \\
\hline Kondziolka et al., $1996^{61}$ & 94.00 & 58.00 & $30 \dagger$ & $1-201$ \\
\hline Young et al., 1997 & 88.20 & 74.50 & - & $1-120$ \\
\hline Kondziolka et al., 1998 & 86.00 & 60.00 & - & - \\
\hline Kannan et al., 1999 & 66.60 & 100.00 & - & $30-90$ \\
\hline Chang et al., 2000 & 100.00 & 46.70 & $18.8^{*}$ & $1-93$ \\
\hline Rogers et al., 2000 & 96.00 & 35.00 & $15^{*}$ & 0-192 \\
\hline Maesawa et al., 2001 & 78.60 & 64.90 & $60 \dagger$ & $0-61.2$ \\
\hline Zheng et al., 2001 & 93.75 & 52.50 & $22^{*}$ & $1-120$ \\
\hline Matsuda et al., 2002 & 100.00 & 60.60 & $17^{*}$ & $0-240$ \\
\hline Pollock et al., 2002 & 75.00 & 59.00 & $21 \dagger$ & $1-140$ \\
\hline Petit et al., 2003 & 77.00 & 42.00 & $21 \dagger$ & $0-168$ \\
\hline Shaya et al., 2004 & 70.00 & 40.00 & - & - \\
\hline Massager et al., 2004 & 89.40 & 68.10 & - & - \\
\hline Cheuk et al., 2004 & 89.60 & 52.10 & $14 \dagger$ & $0-168$ \\
\hline Drzymala et al., 2005 & 81.10 & 52.70 & - & - \\
\hline McNatt et al., 2005 & 75.00 & 32.00 & $38.5^{*}$ & - \\
\hline Sheehan et al., 2005 & 70.00 & 44.00 & $24^{*}$ & $1-180$ \\
\hline Tawk et al., 2005 & 71.00 & 44.00 & - & - \\
\hline Urgosik et al., 2005 & 96.00 & 80.40 & $90 \dagger$ & $1-390$ \\
\hline Régis et al., 2006 & 97.00 & 83.00 & $10 \dagger$ & $0-175$ \\
\hline Longhi et al., 2007 & 90.00 & 61.00 & - & - \\
\hline Little et al., 2008 & 83.00 & 41.00 & - & - \\
\hline Huang et al., $2008^{47}$ & 77.50 & 56.00 & $33^{*}$ & $2-180$ \\
\hline Dellaretti et al., 2008 & 98.70 & - & $78^{*}$ & - \\
\hline Azar et al., 2009 & 83.00 & 40.00 & - & - \\
\hline Han et al., 2009 & 90.20 & 51.70 & - & - \\
\hline Dhople et al., 2009 & 81.00 & 64.00 & $14 \dagger$ & $14-84$ \\
\hline Riesenburger et al., 2010 & 83.00 & 32.10 & $54^{*}$ & $1-180$ \\
\hline Verheul et al., 2010 & 75.00 & 60.00 & - & - \\
\hline Kondziolka et al., 2010 & 89.00 & 28.60 & $30 \dagger$ & $1-360$ \\
\hline Park et al., $2011^{100}$ & - & - & - & - \\
\hline Loescher et al., 2012 & 71.00 & 39.00 & - & - \\
\hline Hayashi et al., 2011 & 98.00 & 66.00 & $21 \dagger$ & - \\
\hline Park \& Hwang, 2011 & 100.00 & - & $28 \dagger$ & $30-480$ \\
\hline Lee et al., 2012 & - & - & - & - \\
\hline Marshall et al., 2012 & 86.00 & 43.00 & - & $1-90$ \\
\hline Elaimy et al., 2012 & 71.00 & 31.00 & - & - \\
\hline Young et al., 2013 & 85.60 & 43.70 & $51.1 \dagger$ & $4.9-81.9$ \\
\hline Lee et al., 2013 & 97.80 & - & - & - \\
\hline Aykol et al., 2014 & 68.80 & 29.00 & $50.4^{*} / 60 \dagger$ & $30-120$ \\
\hline Karam et al., 2014 & 80.50 & 49.00 & $48^{*}$ & $1-180$ \\
\hline Lucas et al., 2014 & 84.50 & - & - & - \\
\hline Régis et al., $2016^{114}$ & 91.75 & - & $10 \dagger$ & $1-180$ \\
\hline \multicolumn{5}{|l|}{ CKR studies } \\
\hline Romanelli et al., 2003 & 70.00 & 40.00 & - & - \\
\hline Lim et al., 2005 & 70.00 & 40.00 & - & - \\
\hline
\end{tabular}


» CONTINUED FROM PAGE 740

TABLE 3. Freedom from pain response and interval to the response

\begin{tabular}{|c|c|c|c|c|}
\hline Authors \& Year & FFP w/ Medication (\%) & FFP w/o Medication (\%) & Mean \&/or Median TTPR (days) & TTPR Range (days) \\
\hline \multicolumn{5}{|l|}{ CKR studies (continued) } \\
\hline Villavicencio et al., 2007 & 67.00 & 67.00 & - & - \\
\hline Fariselli et al., 2009 & 94.00 & - & - & - \\
\hline Adler et al., 2009 & 96.00 & 72.00 & - & - \\
\hline Lazzara et al., 2013 & 88.00 & - & - & - \\
\hline Tang et al., 2011 & - & 68.70 & - & - \\
\hline Peddada et al., 2011 & 100.00 & - & - & - \\
\hline Soboleva et al., 2012 & 50.00 & 50.00 & - & - \\
\hline \multicolumn{5}{|l|}{ LINAC studies } \\
\hline Goss et al., 2003 & 76.00 & 76.00 & $60 \dagger$ & - \\
\hline Smith et al., 2003 & 87.80 & 56.10 & - & - \\
\hline Frighetto et al., 2004 & 95.40 & 68.10 & $81^{*}$ & $0-360$ \\
\hline Kubicek et al., 2004 & 78.00 & 35.00 & - & - \\
\hline Chen et al., 2004 & 90.90 & 43.20 & $28 \dagger$ & - \\
\hline Richards et al., 2005 & 75.00 & 57.00 & $30^{*}$ & - \\
\hline Pusztaszeri et al., 2007 & 100.00 & 35.00 & - & - \\
\hline Zahra et al., 2009 & 95.00 & 40.00 & - & $1-70$ \\
\hline Chen et al., 2010 & 90.90 & 43.20 & $28^{*}$ & - \\
\hline Dos Santos et al., 2011 & 82.70 & 17.30 & - & - \\
\hline Smith et al., 2011 & 88.50 & 71.30 & $57.6^{*}$ & $0-180$ \\
\hline
\end{tabular}

$-=$ not available; TTPR $=$ time to pain relief.

* Mean value.

$\dagger$ Median value.

0.15 , 2-sample t-test), with a difference of $-7.52 \%$ between the means. In contrast, the difference between the GKS and CKR studies was not statistically significant for BNI scores III and IV ( $p=0.81,2$-sample t-test), with a difference of $-1.18 \%$ between the means.

The mean time to recurrence ranged from 6 to 48 months (crude interval 1-150.1 months) for GKS studies, ranged from 7.5 to 20.4 months (crude interval 3-47 months) for LINAC studies, and was 9 months (crude interval 1-43 months) in the only CKR study reporting such data. ${ }^{31}$

\section{Maintaining Pain Relief}

The maintenance of pain relief was very rarely observed in the CKR and LINAC studies, with only Smith et al. ${ }^{125}$ reporting $60 \%$ with pain relief at 3 years. After this time point, the other CKR and LINAC studies did not give details concerning their patients.

For GKS, notable studies reported outcomes at 7 and 10 years, respectively. At 7 years, the following rates of maintained pain relief were reported: Little et al., 32\%:74 Dhople et al., 22\%.25 and Régis et al., 59.7\%. ${ }^{114}$ At 10 years, Kondziolka et al.$^{63}$ and Régis et al. ${ }^{114}$ reported rates of $30 \%$ and $45.3 \%$, respectively.

\section{Discussion}

\section{Timing of RS From Symptom Onset}

Only one study, by Mousavi et al., ${ }^{91}$ retrospectively ana- lyzed a series of 121 patients treated with GKS as their initial surgical procedure (level IV evidence), using a single 4-mm isocenter and a uniform dose of $80 \mathrm{~Gy}$. These authors concluded that earlier GKS (within 3 years of pain onset) led to a shorter time to pain relief, a longer interval of pain relief off medication (BNI score I), and longer adequate pain control (BNI score I-IIIA).

Stereotactic RS yields a better initial FFP response if it is performed in the first 3 years after pain onset (level III evidence).

\section{Possible Radioprotective Effects of Medication at the Time of RS}

Flickinger et al. ${ }^{33}$ investigated the possible radioprotective effects of anticonvulsant medications that could alter the response to RS. They retrospectively analyzed 200 patients who had been treated with a maximal RS dose of 80 Gy and a unique 4-mm collimator, had not undergone previous MVD, and had a follow-up of at least 6 months (median 24 months, range 6-153 months). These authors concluded that the use of carbamazepine or gabapentin at the time of GKS does not reduce the percentage of patients obtaining pain relief and developing complications (facial numbness or paresthesias).

\section{Target (Isocenter) Location and Selection General Considerations}

The technical goal of RS is to place a 4-mm isocenter 
TABLE 4. Summary of complications

\begin{tabular}{|c|c|c|c|c|c|c|c|}
\hline Authors \& Year & $\begin{array}{l}\text { Hypesthesia } \\
\text { Overall } \\
\text { (Mean \%) }\end{array}$ & $\begin{array}{l}\text { Hypesthesia } \\
\text { BNI Scores III } \\
\text { + IV }(\%)\end{array}$ & $\begin{array}{l}\text { Mean Time to } \\
\text { Hypesthesia Onset } \\
\text { in Mos (range) }\end{array}$ & $\begin{array}{l}\text { Other Complications } \\
\qquad(\%)\end{array}$ & $\begin{array}{l}\text { Recurrence } \\
(\%)\end{array}$ & $\begin{array}{l}\text { Mean Time to } \\
\text { Recurrence } \\
\text { (mos) }\end{array}$ & $\begin{array}{l}\text { Range of Time } \\
\text { to Recurrence } \\
\text { (mos) }\end{array}$ \\
\hline \multicolumn{8}{|l|}{ GKS studies } \\
\hline Régis et al., 1995 & 0 & 0 & - & 0 & 20.00 & 10.00 & - \\
\hline Kondziolka et al., $1996^{59}$ & 0 & 0 & - & 0 & - & - & - \\
\hline Kondziolka et al., 199661 & 6.00 & 0 & - & 0 & - & - & - \\
\hline Young et al., 1997 & 0 & 0 & - & 0 & 7.80 & - & - \\
\hline Kondziolka et al., 1998 & 10.00 & 0 & - & 0 & - & - & - \\
\hline Kannan et al., 1999 & - & 0 & - & 0 & 0.00 & - & - \\
\hline Chang et al., 2000 & 13.30 & 0 & 8.5 & 0 & 13.30 & 8.80 & $8-9$ \\
\hline Rogers et al., 2000 & 14.00 & 0 & - & 0 & 21.00 & 6.70 & $1-20$ \\
\hline Maesawa et al., 2001 & - & 0 & 10.2 & $\begin{array}{l}\text { Deafferentation pain } \\
\quad 0.40\end{array}$ & 13.60 & 15.40 & $2-58$ \\
\hline Zheng et al., 2001 & 12.00 & 0 & - & 0 & 9.30 & - & $5-26$ \\
\hline Matsuda et al., 2002 & 17.10 & 0 & $(9-24)$ & Dry eye 9.1 & 9.10 & 8.70 & $6-12$ \\
\hline Pollock et al., 2002 & 37.00 & 0 & $8(2-20)$ & $\begin{array}{l}\text { Bothersome dysesthe- } \\
\text { sia } 12.00\end{array}$ & 16.00 & 8.00 & $2-30$ \\
\hline Petit et al., 2003 & 7.30 & 3.10 & - & 0 & 29.00 & 8.50 & $1-48$ \\
\hline Shaya et al., 2004 & 17.50 & 0 & - & 0 & 42.80 & - & $2-10$ \\
\hline Massager et al., 2004 & 38.00 & 4.30 & - & 0 & 8.00 & 13.20 & - \\
\hline Cheuk et al., 2004 & 11.60 & 1.00 & - & 0 & - & - & - \\
\hline Drzymala et al., 2005 & 43.20 & 16.90 & $(12-15)$ & 0 & - & - & - \\
\hline McNatt et al., 2005 & 20.00 & 9.00 & - & $\begin{array}{l}\text { Keratitis } 7.00 \text {, dyses- } \\
\quad \text { thesia } 16.00\end{array}$ & 23.00 & 9.60 & $2-36$ \\
\hline Sheehan et al., 2005 & 19.00 & 10.30 & - & 0 & 27.00 & 12.00 & $2-34$ \\
\hline Tawk et al., 2005 & 37.00 & 0 & - & Paresthesia 13.00 & - & - & - \\
\hline Urgosik et al., 2005 & 20.00 & 0 & $36(3-94)$ & 0 & 25.00 & 36.00 & $6-94$ \\
\hline Régis et al., 2006 & 5.00 & 0 & - & Paresthesia 5.00 & 34.00 & 6.00 & $1-15$ \\
\hline Longhi et al., 2007 & 2.50 & 0 & 8.4 & Paresthesia 6.25 & 18.00 & 14.20 & - \\
\hline Little et al., 2008 & 45.00 & 17.00 & - & Dry eye 6.7 & - & - & - \\
\hline Huang et al., $2008^{47}$ & 14.00 & 2.00 & $6(1-36)$ & Keratitis 3.4 & - & - & - \\
\hline Dellaretti et al., 2008 & 21.00 & 10.50 & - & 0 & 26.30 & - & $6-42$ \\
\hline Azar et al., 2009 & 13.00 & 0 & - & 0 & - & - & - \\
\hline Han et al., 2009 & 13.30 & 0 & $(2-52)$ & 0 & 52.20 & - & - \\
\hline Dhople et al., 2009 & - & 6.00 & - & 0 & - & - & - \\
\hline Riesenburger et al., 2010 & 35.80 & 0 & - & 0 & 27.00 & 9.50 & $4-54$ \\
\hline Verheul et al., 2010 & 29.00 & 6.00 & - & $\begin{array}{l}\text { Deafferentation pain } \\
\quad 0.30\end{array}$ & - & - & - \\
\hline Kondziolka et al., 2010 & 10.50 & 3.20 & - & $\begin{array}{l}\text { Deafferentation pain } \\
\quad 0.20\end{array}$ & 42.90 & 48.00 & $3-144$ \\
\hline Park et al., $2011^{100}$ & 21.00 & 0 & - & Dry eye 1.6 & - & - & - \\
\hline Loescher et al., 2012 & 31.00 & - & - & 0 & - & - & - \\
\hline Hayashi et al., 2011 & 11.70 & 12.30 & - & 0 & 18.00 & - & - \\
\hline Park \& Hwang, 2011 & 23.50 & 0 & - & Dry eye 5.8 & 35.30 & 20.00 & $3-36$ \\
\hline Lee et al., 2012 & - & 0 & - & Dysesthesia 4.54 & - & - & - \\
\hline Marshall et al., 2012 & 52.00 & 0 & - & $\begin{array}{l}\text { Deafferentation pain } \\
\text { 3.30, keratitis } 2.7 \\
\text { (corneal anesthesia) }\end{array}$ & 40.00 & - & - \\
\hline Elaimy et al., 2012 & 19.00 & 0 & - & Paresthesia 7.00 & - & - & - \\
\hline Young et al., 2013 & 32.90 & 17.30 & - & Dry eye 22.4 & 14.30 & - & - \\
\hline
\end{tabular}


TABLE 4. Summary of complications

\begin{tabular}{|c|c|c|c|c|c|c|c|}
\hline Authors \& Year & $\begin{array}{l}\text { Hypesthesia } \\
\text { Overall } \\
\text { (Mean \%) }\end{array}$ & $\begin{array}{l}\text { Hypesthesia } \\
\text { BNI Scores III } \\
\text { + IV (\%) }\end{array}$ & $\begin{array}{l}\text { Mean Time to } \\
\text { Hypesthesia Onset } \\
\text { in Mos (range) }\end{array}$ & $\begin{array}{l}\text { Other Complications } \\
(\%)\end{array}$ & $\begin{array}{l}\text { Recurrence } \\
(\%)\end{array}$ & $\begin{array}{l}\text { Mean Time to } \\
\text { Recurrence } \\
\text { (mos) }\end{array}$ & $\begin{array}{c}\text { Range of Time } \\
\text { to Recurrence } \\
\text { (mos) }\end{array}$ \\
\hline \multicolumn{8}{|l|}{ GKS studies (continued) } \\
\hline Lee et al., 2013 & 37.40 & 13.20 & - & 0 & 15.40 & 32.00 & $10-62$ \\
\hline Aykol et al., 2014 & 68.80 & 0 & - & Dysesthesia 68.80 & - & - & - \\
\hline Karam et al., 2014 & 16.70 & 11.1 (IV) & - & 0 & 41.40 & - & - \\
\hline Lucas et al., 2014 & 42.00 & - & - & 0 & 50.44 & - & - \\
\hline Régis et al., $2016^{114}$ & 21.10 & 2.20 & 12 & 0 & 34.40 & 24.00 & $0.6-150.1$ \\
\hline \multicolumn{8}{|l|}{ CKR studies } \\
\hline Romanelli et al., 2003 & - & 10.00 & - & 0 & - & - & - \\
\hline Lim et al., 2005 & 51.20 & - & - & 0 & 15.80 & - & - \\
\hline Villavicencio et al., 2007 & 47.00 & 12.00 & - & 0 & 31.00 & - & - \\
\hline Fariselli et al., 2009 & - & - & - & 0 & 33.00 & 9.00 & $1-43$ \\
\hline Adler et al., 2009 & 17.00 & - & - & 0 & - & - & - \\
\hline Lazzara et al., 2013 & 11.80 & 5.90 & - & 0 & 23.50 & - & - \\
\hline Tang et al., 2011 & 18.75 & - & - & 0 & - & - & - \\
\hline Peddada et al., 2011 & $\begin{array}{l}\text { Oral muco- } \\
\text { sitis }\end{array}$ & - & - & 0 & - & - & - \\
\hline Soboleva et al., 2012 & - & - & - & 0 & - & - & - \\
\hline \multicolumn{8}{|l|}{ LINAC studies } \\
\hline Goss et al., 2003 & 32.00 & - & - & 0 & 32.00 & - & $4-13$ \\
\hline Smith et al., 2003 & 25.00 & - & - & 0 & 25.60 & 7.46 & $3-10$ \\
\hline Frighetto et al., 2004 & 36.30 & - & - & 0 & 36.30 & 8.50 & $6-11$ \\
\hline Kubicek et al., 2004 & 25.00 & - & - & Dry eye 5.0 & 63.00 & 20.40 & $2-36$ \\
\hline Chen et al., 2004 & 11.40 & - & - & 0 & 25.00 & - & - \\
\hline Richards et al., 2005 & 14.00 & - & - & Keratitis 3.60 & - & - & - \\
\hline Pusztaszeri et al., 2007 & - & - & - & 0 & 29.00 & - & $4-13$ \\
\hline Zahra et al., 2009 & 35.00 & - & - & 0 & - & - & - \\
\hline Chen et al., 2010 & 11.40 & - & - & 0 & 25.00 & - & - \\
\hline Dos Santos et al., 2011 & 36.00 & - & - & 0 & 34.60 & 20.00 & $4-47$ \\
\hline Smith et al., 2011 & 49.70 & 13.60 & - & Dry eye 19.5 & 19.00 & 13.50 & - \\
\hline
\end{tabular}

$-=$ not available.

(in GKS) or 5- or 7.5-mm collimator (in CKR or LINAC RS) on the trigeminal nerve as it courses the prepontine cistern. This technical choice is made since the nerve, surrounded by CSF at this level, is very well visualized using modern MRI techniques. These imaging techniques also allow for precise targeting and a very sharp dose fall-off (for example, penumbra) beyond the trigeminal nerve, reducing the risk of damage to the brainstem and/or temporal lobe.

\section{Different Targets: From Leksell to Now}

In a study published in 1991, Lindquist, who used the same target (gasserian ganglion) in all cases, evaluated and reported outcomes for 46 patients, $18 \%$ of whom had maintained pain relief at 2 years. ${ }^{3}$ In 1993, Rand et al. proposed moving the target to the cisternal segment of the trigeminal nerve, to what was called the "retrogasserian" or "far anterior cisternal" target (Fig. 2). ${ }^{109,115}$ Lindquist subsequently promoted the elegant idea of targeting the REZ (also referred to as the "dorsal REZ" in the literature) where the nerve exits the brainstem with a lower dose of 70 Gy. ${ }^{3}$ Kondziolka et al..$^{63}$ and Régis et al. ${ }^{114}$ reported the results for FFP without medication at 10 years after targeting the REZ and the anterior cisternal target, respectively. These 2 studies are the only ones reporting such long-term follow-up.

Note, however, that anatomical placement of the target varies from 0 to $8 \mathrm{~mm}$ with regard to the nerve's exit from the brainstem.

\section{Rationale for Target Placement: A Histological Hypothesis}

The major difference between the anterior and the posterior target probably relates to the dose received by the REZ and the brainstem and, more precisely, to the trigeminal nerve pathways within the brainstem. The REZ, also called the "Obersteiner-Redlich zone," is histologically de- 
fined as the place where peripheral myelination (Schwann cells) transitions to central myelination (oligodendrocytes). The REZ is not fixed, and its location can vary from 0 to 3 $\mathrm{mm}$ from the nerve's exit from the brainstem and is impossible to visualize on in vivo imaging. Some authors make the choice of an anterior versus a posterior target based on the idea that the nerve is more radiosensitive at the REZ than at the anterior part.

\section{Target Placement and Related Complications: Indirect Evidence From Dose-Volume Histograms}

Only 1 study documented dose-volume effects on the brainstem (dose-volume histogram [DVH]) in a comparison of 3 different devices: GK, LINAC, and CK. ${ }^{142}$ Xue et al.'s aim was to see whether complications after RS were correlated with dose distributions. These authors reviewed 32 cases that had been treated with GKS at their institution (Cooper University Hospital). All cases had utilized doses of either 80 or $85 \mathrm{~Gy}$, had not been previously treated with surgery, and had a median follow-up of 25 months (range 4-39 months). The LINAC cases were obtained from the study of Gorgulho et al., ${ }^{40}$ and the CK cases were obtained from Lim et al. ${ }^{72}$ Xue et al. concluded that the most common complication was numbness. ${ }^{142}$ In the following cited GKS studies ${ }^{61,85,112,137,142}$ numbness was the only complication encountered, while other adverse events such as eye irritation and/or dryness, ${ }^{125}$ neurotrophic keratopathy, ${ }^{116}$ anesthesia dolorosa, decreased corneal reflex, ipsilateral masticator weakness, trismus, ${ }^{72}$ and dysesthesias ${ }^{138}$ appeared in the LINAC and CKR studies.

Brisman and Mooij ${ }^{15}$ evaluated radiosurgical efficacy in a series of patients, considering the association between the brainstem volume included in the $20 \%$ isodose line (VB20) and the volume of the trigeminal nerve that receives $50 \%$ or more of the maximum dose (VT50). These authors concluded that excellent results at 6 and 12 months positively correlated with VB20 values of $20 \mathrm{~mm}^{3}$ or more $(\mathrm{p}=0.018)$. However, this study lacked long-term followup and, consequently, has limited analysis with regard to complication rates and their significant factors, as well as with regard to recurrence.

The worst complication reported with GKS was dry eye syndrome, in the study by Matsuda et al., ${ }^{89}$ who used the REZ target. While evaluating the DVHs, these authors determined that the maximal dose to the brainstem (cutoff $>$ $25 \mathrm{~Gy}$ ), as well as the position of the isocenter (cutoff $<4.5$ $\mathrm{mm}$ ) in relation to the exit of the trigeminal nerve from the brainstem, was statistically significantly related to complications. Additionally, a brainstem volume of more than 28 $\mathrm{mm}^{3}$ receiving more than 12 Gy of radiation was significantly related to complications (the only significant factor in the multivariate analysis).

Goss et al. conducted a study using LINAC RS and found a trend toward increased facial numbness when larger volumes of the brainstem were included in the $20 \%$ isodose line treatment plan. ${ }^{42} \mathrm{~A}$ similar (though not statistically significant) tendency was reported by Massager et al., ${ }^{85}$ who found that patients with facial numbness had received higher radiation doses to the brainstem than the patients with no facial numbness. That is, for the first $1 \mathrm{~mm}^{3}$ of the brainstem, a median dose of 12.85 Gy compared with $10.6 \mathrm{~Gy}$, respectively, had been administered. And for the first $10 \mathrm{~mm}^{3}$ of the brainstem, $10.6 \mathrm{~Gy}$ compared with 8.6 Gy had been delivered.

Cheuck et al. did not find any correlation between the appearance of facial numbness and the dose received by the brainstem. ${ }^{21}$ This is not surprising, however, as the doses delivered to the brainstem were rather low in their study, mostly ranging from 7 to 17.5 Gy (median 15 Gy), with $94.8 \%$ of the patients receiving a maximal dose $\leq 15$ Gy $(p=0.6832)$. Moreover, the authors used plugging to limit doses to the brainstem. Neither was there a correlation between the FFP response and the dose administered to the brainstem.

Indirect evidence for target placement also comes from the study by Smith et al., ${ }^{125}$ who compared 3 different strategies with regard to the brainstem and maximal dose. The first group was treated with 70 Gy at the $30 \%$ isodose line, a second group received 90 Gy at the $30 \%$ isodose line, and a third group received $90 \mathrm{~Gy}$ at the $50 \%$ isodose line. The incidence of facial numbness increased from $35.7 \%$ to $48.9 \%$ to $59.3 \%$, respectively.

In a study of 448 patients treated with a mean dose of 88 Gy (range 80-97 Gy) targeting the REZ, Marshall et al. found that the mean delivered dose in those who developed facial numbness $(57.6 \mathrm{~Gy})$ was higher than that in the patients without numbness $(47.3 \mathrm{~Gy} ; \mathrm{p}=0.02){ }^{83}$

Régis et al. ${ }^{114}$ recently published a large series of 497 patients with more than 1 year of follow-up (median 4 years, range 1-14). The authors limited irradiation to 10 $\mathrm{mm}^{3}$ of the brainstem with a maximum dose of $15 \mathrm{~Gy}$, using an anterior retrogasserian target. They reported $21 \%$ of patients with hypesthesia and $45.3 \%$ of patients with FFP without medication at 10 years.

\section{Anterior Versus Posterior Target: Comparative and Retrospective Clinical Studies}

Matsuda et al. ${ }^{88}$ divided 100 patients treated with a single 4-mm isocenter into 2 different groups according to target-posterior target group, receiving $80 \mathrm{~Gy}$ at the proximal trigeminal nerve (REZ), and anterior target group (cisternal), receiving doses between 80 and 90 Gy at the retrogasserian portion of the trigeminal nerve. The median follow-up was 30 months (range 3-88 months). Initial and last follow-up pain relief were similar in the 2 groups $(81.6 \%$ and $67.4 \%$ anterior compared with $92.2 \%$ and $68.6 \%$ posterior, respectively), as was the total percentage of complications ( $44.9 \%$ vs $37.3 \%$, respectively). However, the authors found more bothersome complications in the anterior group (26.5\% vs $11.8 \%)$, but there had been a significant increase in the prescribed dose $(88.5 \pm$ 3.6 vs $80 \mathrm{~Gy}$ ) and the target had been very close to the plexus triangularis, as initially described by Leksell. Thus, the work of Matsuda et al. cannot be considered a true comparison between the anterior (as described by Régis et al. ${ }^{114}$ ) and posterior target.

Park et al. ${ }^{99}$ retrospectively compared 2 different targeting methods of the retrogasserian versus the dorsal REZ. Thirty-nine cases were retrospectively reviewed after a mean follow-up of 26.1 months (range 12-53 months). Those with an anterior target had received a median dose of 85 Gy (mean 85.6 Gy, range 83-90 Gy) compared with 


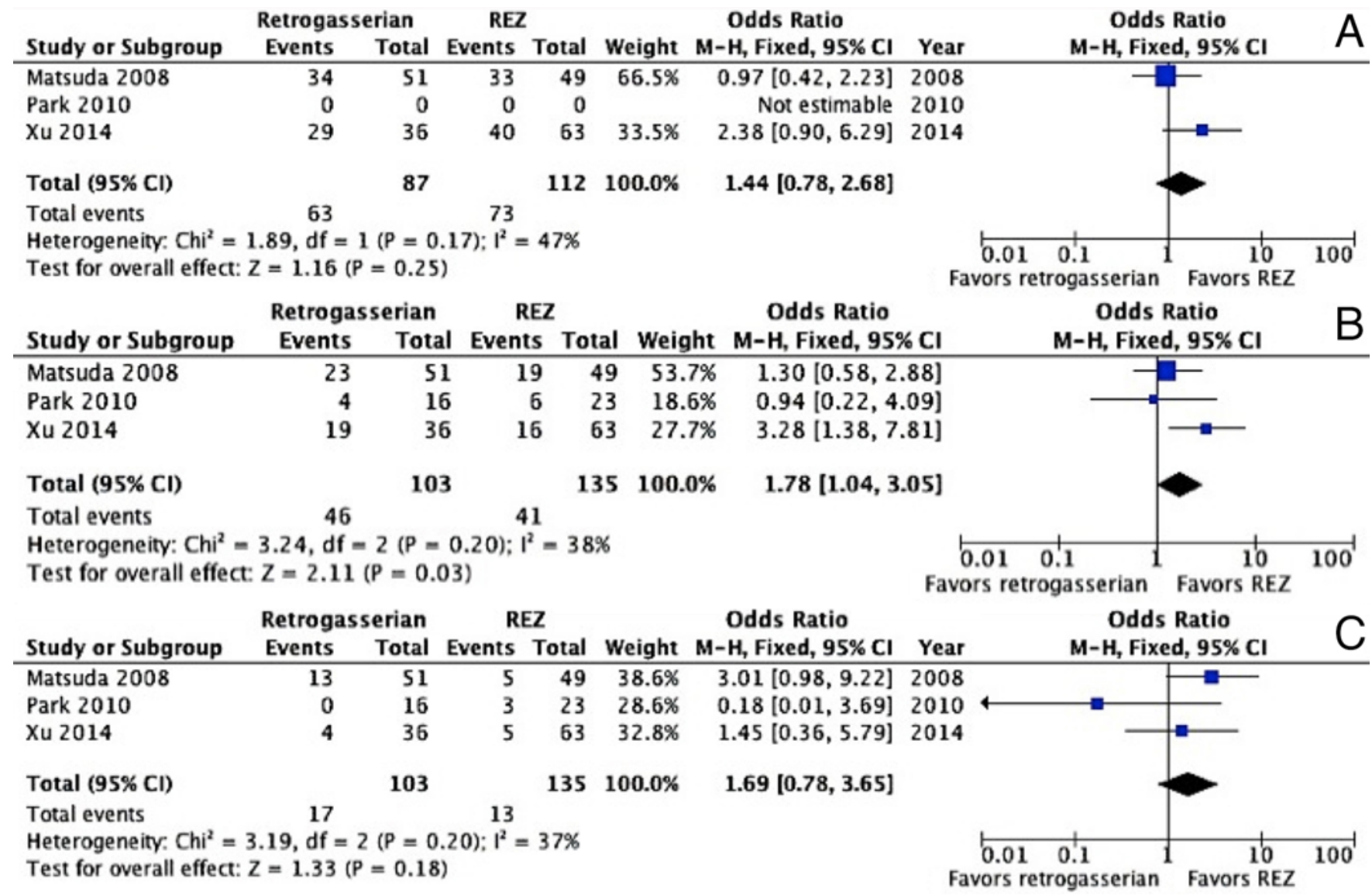

FIG. 3. When initial efficacy was pooled (A), there was no statistically significant difference between the retrogasserian and the REZ target, with an $\mathrm{HR}=1.44(95 \% \mathrm{Cl} 0.78,2.68), \mathrm{p}=0.25$. For toxicity $(\mathrm{B})$, there was a statistically significant increase in the REZ group, with an $\mathrm{HR}=1.78(95 \% \mathrm{Cl} 1.04,3.05), p=0.03$. For the maintenance of pain relief $(\mathbf{C})$, there was no statistically significant difference between the two targets, with an $\mathrm{HR}=1.69(95 \% \mathrm{Cl} 0.78,3.65), p=0.18$. Figure is available in color online only.

80 Gy (mean 82.6 Gy, range $80-90$ Gy) in the posterior group. Initial pain relief was fairly comparable between the two groups, at $93.8 \%$ for the anterior group versus $87 \%$ for the posterior group. The time to a response to GKS was shorter in the anterior group, at a mean of 4.1 weeks compared with 6.4 weeks in the posterior group. While the total complication rate was similar in the two groups $(25 \%$ anterior vs $26.1 \%$ posterior), bothersome facial numbness and dry eye syndrome were never encountered in the anterior group but did occur in the posterior group (13.1\% and $8.7 \%$, respectively). The authors concluded that for a similar range of doses, the anterior target had better outcomes with a similar rate of pain relief but with fewer bothersome complications.

$\mathrm{Xu}$ et al. ${ }^{141}$ retrospectively reviewed 99 cases treated with GKS at the same institution, targeting either the REZ (63 patients) or the retrogasserian portion (36 patients) with a maximum dose of 80 Gy. Kaplan-Meier analysis revealed that the durability of pain relief was only associated with the proximal location of the target $(\mathrm{p}=0.018)$. Radiosurgery-induced facial numbness (BNI score II or III) was more frequent in the proximal REZ group than in the distal group (53\% vs $25 \%$, respectively, $\mathrm{p}=0.015$ ).

Figure 3 shows the results for comparisons of the ret- rogasserian versus the REZ target. When initial efficacy was pooled, there was no statistically significant difference between the two targets, with an HR $=1.44$ (95\% CI 0.78, 2.68 ), $p=0.25$ (Fig. 3A). For toxicity, there was a statistically significant increase in the REZ group, with an HR = 1.78 (95\% CI 1.04, 3.05), $p=0.03$ (Fig. 3B). For the maintenance of pain relief, there was no statistically significant difference between the two targets, with an HR $=1.69$ (95\% CI 0.78, 3.65), $\mathrm{p}=0.18$ (Fig. 3C; level II evidence).

Currently, given level II evidence, the ISRS favors an anterior target. This preference is mainly based on retrospective comparative studies, which have demonstrated that the anterior retrogasserian target has, in terms of FFP, an outcome similar to that with a posterior target but with a less bothersome hypesthesia complication, no development of other complications, and extended long-term pain relief. Furthermore, from the studies analyzing DVHs, there is evidence that increasing the dose to the REZ and/ or the brainstem (VB20, VB50, and so forth) will increase the probability of numbness. The funnel plots including the comparative studies show a statistically significant effect in favor of the anterior target, with similar initial efficacy, less toxicity, and extended FFP on a long-term basis.

Anterior and posterior targets have similar initial effi- 


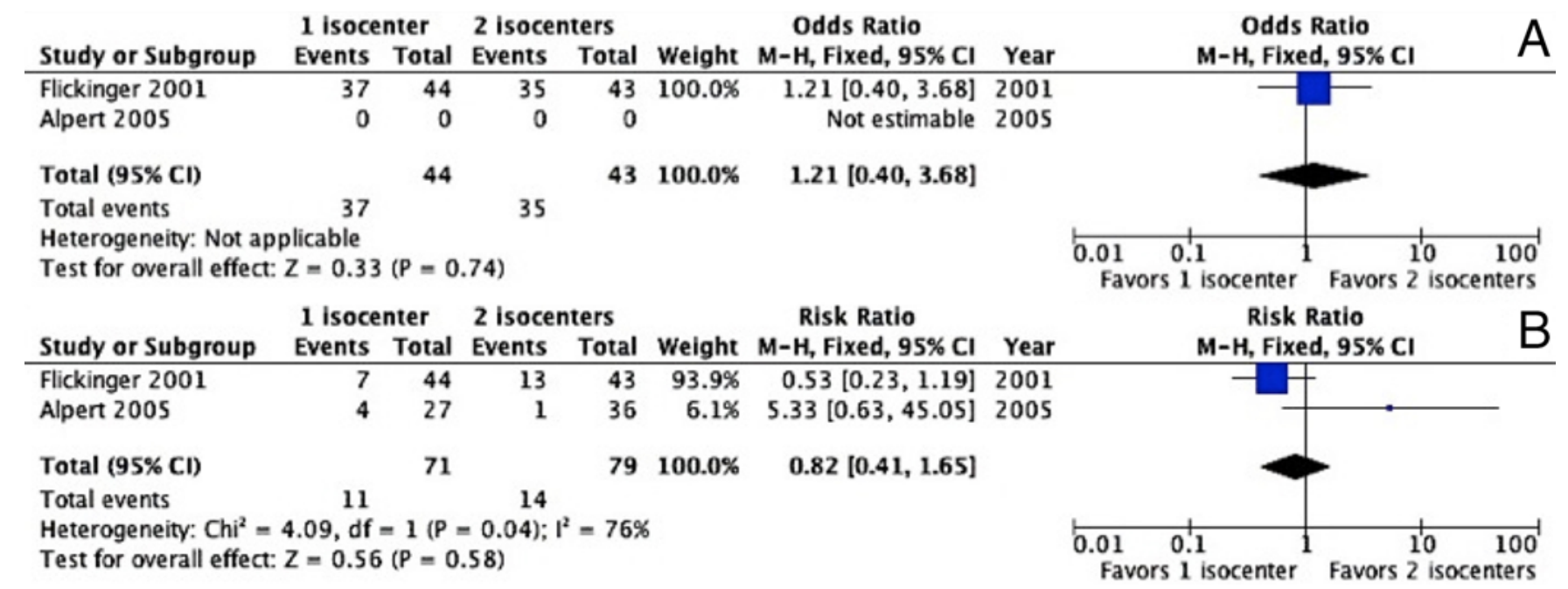

FIG. 4. When initial efficacy was pooled (A), there was no statistically significant difference between 1 and 2 isocenters, with an $H R=1.21(95 \% \mathrm{Cl} 0.40,3.68), p=0.74$. For toxicity $(B)$, there was no statistically significant difference in the number of isocenters used, with an $\mathrm{HR}=0.82(95 \% \mathrm{Cl} 0.41,1.65), p=0.58$; however, the study by Flickinger et al ${ }^{32}$ clearly shows a major increase in toxicity with 2-isocenter use. Figure is available in color online only.

cacy (level II evidence). The anterior target has lower hypesthesia and bothersome hypesthesia rates than the posterior target (level II evidence). Additional complications, including dry eye syndrome, are seen only with the posterior target (level II and III evidence). The anterior target, as compared to the posterior one, may result in higher pain relief rates on a long-term basis (level II and III evidence).

\section{Isocenters: Their Number and the Use of Concentric Ones One Versus Two Isocenters}

Flickinger et al. ${ }^{32}$ organized a prospective, double-blind randomized study (the only current randomized trial on stereotactic RS for TN) including 87 patients treated with 75 Gy using either one (44 patients) or two (43 patients) 4-mm isocenters at a retrogasserian target. After a median follow-up of 26 months (range 1-36 months), though pain relief was similar in the two groups, the authors concluded that the use of 2 isocenters significantly increases complications, mainly hypesthesia (including the bothersome type), due to the increase in the volume of the treated nerve $(\mathrm{p}=0.018)$.

The question on the number of isocenters to use was also addressed by Alpert et al. ${ }^{4}$ in a cohort of 63 patients undergoing GKS with either one (27 patients) or two (36 patients) 4-mm isocenters at the REZ, using doses of 70-95 Gy. These authors concluded that patients treated with two isocenters were more likely to receive a higher radiation dose (mean 88.3 vs $79.1 \mathrm{~Gy}, \mathrm{p}<0.001$ ) and have a greater improvement score (mean 2.83 vs $1.72, \mathrm{p}=0.003$ ). Hypesthesia appeared in 5 cases ( 1 in the two-isocenters group and 4 in the one-isocenter group, all mild cases). Median follow-up was 10 months (range 3-63 months).

Pollock et al. ${ }^{106}$ described the length of nerve treated with one or two 4-mm isocenters, which (within the $50 \%$ isodose line) was a median of $5.9 \mathrm{~mm}$ (range $5.2-6.3 \mathrm{~mm}$ ) in the first group (one isocenter) compared with $9.4 \mathrm{~mm}$ (range 7.4-11 mm) in the second (two isocenters). The au- thors found no significant relationship between the length of irradiated nerve and post-RS complications.

Dos Santos et al. ${ }^{26}$ documented 3 cases of brainstem edema while reporting outcomes for essential TN treated with LINAC RS. Interestingly, the authors had used 2 collimators in these cases and stated that the use of 2 rather than 1 collimator had increased the median dose to the brainstem (from 4.5 to $7.2 \mathrm{~Gy}$, respectively). They subsequently abandoned the use of 2 collimators.

Figure 4 shows the results of comparisons in the number of isocenters used. When initial efficacy was pooled, there was no statistically significant difference between 1 and 2 isocenters, with an $\mathrm{HR}=1.21(95 \%$ CI $0.40,3.68)$, $\mathrm{p}=0.74$ (Fig. 4A). For toxicity, there was no statistically significant difference in the number of isocenters used, with an $\mathrm{HR}=0.82$ (95\% CI 0.41, 1.65), $\mathrm{p}=0.58$ (Fig. 4B); however, the study by Flickinger et al. clearly shows a major increase in toxicity with the use of 2 isocenters (the so-called Flickinger effect, level II evidence). ${ }^{32}$

\section{One 4-mm Isocenter Versus Concentric 4- and 8-mm Isocenters}

The issue of one 4-mm isocenter compared with concentric 4- and 8- $\mathrm{mm}$ isocenters was addressed by Kanner et al. ${ }^{54}$ who retrospectively reviewed 101 cases treated with GKS using either a single 4-mm isocenter (54 patients) or combined 4- and 8-mm isocenters (47 patients). A maximal dose of $75 \mathrm{~Gy}$ was targeted at the retrogasserian part of the trigeminal nerve. The authors concluded that the use of combined concentric isocenters did not improve outcome in terms of efficacy but did significantly increase numbness $(22.6 \%$ compared with $2.9 \%$ at 2 years, $\mathrm{p}=0.0002$; level II evidence).

\section{A Longer Segment of Treated Nerve and the Integral Dose to the Nerve}

In a bicentric comparative study, ${ }^{86}$ Massager et al. analyzed a cohort of 358 patients (259 treated in Marseille and 
109 treated in Brussels) who had undergone 3 different targeting strategies: 90 Gy and no beam channel blocking (Marseille only, group 1), 90 Gy and no blocking (Brussels and Marseille, group 2), and $90 \mathrm{~Gy}$ with blocking (Brussels only, group 3). The radiation dose delivered to the nerve root in these 3 groups was significantly associated with the incidence of mild $(15 \%, 21 \%$, and $49 \%$, respectively) and bothersome $(1.4 \%, 2.4 \%$, and $10 \%$, respectively) trigeminal dysfunction. The good pain relief rates were $81 \%$, $85 \%$, and $90 \%$, respectively, and the excellent pain relief rates were $66 \%, 77 \%$, and $84 \%$, respectively. The authors concluded that the use of a similar target, the incidence of trigeminal dysfunction, and pain relief can vary according to the radiation energy received by the retrogasserian portion of the trigeminal nerve root (mean respective doses: 32.17, 38.01, and 42.86 Gy). The prescription dose and the use of channel blocking modify the integral dose to the nerve $(2.18,2.76$, and $3.28 \mathrm{~mJ}$, respectively).

In another study, Massager et al ${ }^{87}$ retrospectively analyzed 109 patients who had been treated with GKS using an anterior cisternal target and a dose of 90 Gy. In 49 patients, beam channel blocking was used to reduce the dose delivered to the brainstem; 60 cases were treated without blocking. The authors found that channel blocking was significantly associated with a longer length of nerve exposed to high-dose radiation and a higher mean dose (42.86 Gy vs $38.01 \mathrm{~Gy}$, respectively, $\mathrm{p}=0.002$ ) to the trigeminal nerve. More patients with blocking achieved an excellent pain outcome ( $84 \%$ vs $62 \%$ ) but had a higher incidence of moderate and bothersome hypesthesia (37\% and $10 \%$ vs $30 \%$ and $2 \%$, respectively). Therefore, the authors recommend avoiding beam channel blocking for a 90-Gy dose since this increases the length of the treated nerve and thus toxicity. Additionally, the integral doses within the nerve were 3.35 and $3.12 \mathrm{~mJ}$, respectively $(\mathrm{p}=0.027)$.

Villavicencio et al. ${ }^{138}$ analyzed outcomes for patients who had undergone CKR and concluded that treating longer lengths of the nerve was associated with both better pain relief and a higher incidence of hypesthesia. In another CKR study, Lim et al. ${ }^{71}$ retrospectively analyzed 29 patients in whom a length between 6 and $8 \mathrm{~mm}$ of the cisternal portion of the trigeminal nerve was irradiated using a median dose of 66.4 Gy (range 60-70 Gy) based on CT cisternography. While initial pain relief was excellent $(90 \%)$ with a short latency to pain relief (median 6 days), the complication rate was high. A moderate or severe increase in trigeminal dysfunction was found in 4 (14\%) and $3(10 \%)$ patients, respectively. A decrease in the corneal reflex was found in $6.9 \%$ of the cases. Anesthesia dolorosa was found in $6.9 \%$, as was ipsilateral masticatory weakness, with 1 patient $(3.45 \%)$ presenting with transient diplopia.

Do not increase the length of the treated nerve: use only one 4-mm isocenter. Using 2 isocenters (either continuously or concentrically) yields similar rates of initial efficacy but with increased toxicity (the so-called Flickinger effect). Do not use beam channel blocking at 90 Gy (level I and II evidence).

\section{Dose Selection}

The optimal maximal dose selection remains a matter of debate. The doses delivered with RS usually vary from
60 to $90 \mathrm{~Gy}$. It is worth noting that target selection and dose prescription are not done in the same manner for all RS techniques. In general, while dose is prescribed "on one point" in GKS, there is instead a dose prescription for a certain volume in LINAC RS or CKR. Typically, pain relief is considered modest with doses less than 80-90 Gy, whereas an overdose (more than $90 \mathrm{~Gy}$ ) can lead to similar rates of pain relief but more complications. Most articles consider a dose between 70 and 90 Gy for a primary treatment, but which dose is optimal on an individual basis is unknown.

Kondziolka et al. ${ }^{59}$ was the first to address this issue in a study of 51 patients with typical TN, treated with a dose range between 60 and $90 \mathrm{~Gy}$. The authors concluded that a maximum dose of $70 \mathrm{~Gy}$, as compared with $60 \mathrm{~Gy}$, was associated with a significantly greater chance of complete pain relief $(\mathrm{p}=0.04)$. This conclusion has been confirmed by a multicentric study by the same group, ${ }^{61}$ which found dose to be the unique factor influencing the complete response rate (including initial and last follow-up) in a multivariate analysis $(\mathrm{p}=0.016)$. Note, however, that the former study included multiple target strategies, heterogeneous criteria for patient inclusion, and so forth.

Shaya et al. ${ }^{120}$ also evaluated dose as a predictive factor. Among a series of 40 patients, 4 were treated with $70 \mathrm{~Gy}$, 32 with $80 \mathrm{~Gy}$, and 4 with $90 \mathrm{~Gy}$. The failure rate at the last follow-up was significantly associated with dose (70 Gy with $100 \%$ failure vs 80 or 90 Gy with $22.2 \%$ failure, $\mathrm{p}=0.04)$.

Kim et al. ${ }^{58}$ addressed the issue of dose within the framework of a retrospective study of an REZ target (situated 2-4 $\mathrm{mm}$ anterior to the entrance of the nerve into the brainstem) in a series of 104 patients treated with doses of 80 Gy (60 patients) and 85 Gy (44 patients). The authors concluded that the use of 85 Gy brought more rapid clinical improvement without causing more complications. The 3-year actuarial FFP rate was similar between the two dose groups, $61.2 \%$ compared with $60.3 \%$.

Longhi et al..$^{77}$ evaluated dose in a retrospective study that included 160 patients treated with 1 isocenter at a distance $2-5 \mathrm{~mm}$ from the exit of the nerve, using a mean dose of 85 Gy (range 75-95 Gy). In a univariate ( $p=$ $0.007)$ and multivariate $(\mathrm{p}=0.0001)$ analysis, a maximal dose greater than 80 Gy was significantly related to a BNI score I outcome and a pain-free outcome, respectively. Additionally, $70 \%$ of the encountered complications occurred in patients treated with a dose higher than 90 Gy. The authors concluded that even though a maximal dose $>90$ Gy is linked to a more favorable outcome, it can also lead to a higher incidence of complications. We have therefore concluded that a maximal dose of $90 \mathrm{~Gy}$ is an appropriate upper limit. ${ }^{63,106,114,115,125}$

Indirect evidence also comes from histological studies. Zhao et al. ${ }^{148}$ irradiated the trigeminal nerve in 5 rhesus monkeys, with doses ranging from 60 to 100 Gy $(60,70$, 80 , or $100 \mathrm{~Gy}$ ). They concluded that doses of 60 and $70 \mathrm{~Gy}$ have very little impact on the structure of the trigeminal nerve, whereas a dose of 80 Gy can cause partial degeneration with the loss of axons and demyelination. Importantly, doses of $100 \mathrm{~Gy}$ can cause some necrosis of neurons. The mechanism of pain relief is believed to be focal axonal de- 
generation of the trigeminal nerve that affects pain fibers proportionally more than sensory fibers..$^{60,128}$

The minimal effective dose is $70 \mathrm{~Gy}$ (level II evidence). The maximal effective dose is 90 Gy (level III evidence). Beyond 90 Gy, the efficacy rate remains similar but with a higher complication rate (level III evidence).

\section{Dose Rate Influence}

The literature regarding the influence of the radiation dose rate on outcomes after treating classical TN with GKS comprises very few studies ${ }^{6,10}$ despite a large number of trials confirming the safety and efficacy of GKS as a first-line and/or second-line treatment. ${ }^{113}$ Balamucki et al. ${ }^{10}$ concluded that there is no observable effect of dose rate or treatment duration on the control of facial pain and that patients should be confident in receiving optimal care with GKS at any time during the first half-life of cobalt sources. Arai et al. ${ }^{6}$ recommended no adjustment in the maximum dose to the treated nerve in a TN procedure when the GK is operating within a radiation dose rate range of 1.21-3.74 $\mathrm{Gy} / \mathrm{min}$. More recently, Lee et al. ${ }^{68}$ suggested that a higher dose rate may provide earlier and longer-lasting pain relief (dose rate $>2 \mathrm{~Gy} / \mathrm{min}$ ), along with a lower recurrence rate at a later follow-up. These findings were obtained in a study of 133 patients uniformly treated with a dose of 80 Gy, with a single 4-mm isocenter without blocking, and within a dose rate range from 1.28 to $2.95 \mathrm{~Gy} / \mathrm{min}$.

\section{Single-Fraction Versus Hypofractionated RS}

Fraioli et al. ${ }^{36}$ retrospectively evaluated 23 patients who had undergone single-fraction RS (40 Gy) versus 22 patients who had been treated with hypofractionated stereotactic radiotherapy (HSRT; total dose 72 Gy in 6 fractions), delivered to the retrogasserian cisternal portion of the trigeminal nerve. The mean follow-up was 3.9 years. A BNI score of I-IIIB was achieved in $95.6 \%$ of patients treated with single-fraction RS and $100 \%$ of those treated with HSRT. The recurrence rate was lower in the singlefraction group (8.7\% vs $27.3 \%$ ), whereas facial numbness appeared in $8.7 \%$ of cases in the single-fraction group and none in the other group. The authors concluded that singlefraction RS resulted in more effective pain control than HSRT.

Single-fraction RS is better than hypofractionated RS (level II evidence).

\section{Targeting the Trigeminal Nerve Based Only on CT Images}

Four studies addressed the issue of targeting the trigeminal nerve with CT, 3 GKS studies and 1 CKR study, each using either CT only or CT cisternography.7,71,96,140 The study by Park et al. included 21 patients who were treated with a median dose of $80 \mathrm{~Gy}$ and had a median follow-up of 35 months. ${ }^{96}$ Treatment outcomes were compared with those in 459 patients who had undergone MRIguided GKS for TN at the same institution. These authors concluded that the rate of pain relief was similar in the 2 patient groups. They additionally indicated that, for cases involving the use of a head frame, the posterior pins should be placed at least $1 \mathrm{~cm}$ away from the inion to reduce pinand frame-related artifacts on the targeting CT.
In patients with medically refractory $\mathrm{TN}$ who are unsuitable for MRI, CT targeting remains an appropriate option. Computed tomography is likely to ensure that the treated population will not have a higher rate of toxicity and/or pain recurrence.

\section{Factors Influencing Initial or Later Pain Relief and Associated Complications \\ General Aspects}

Several variables have been associated with the initial FFP response. Positive predictors before RS are an increased age, ${ }^{83,121}$ age more than 70 years, ${ }^{43,57}$ and typical pain. ${ }^{77}$ Negative predictors before RS include multiple sclerosis, ${ }^{13,62,76,90,112,137}$ prior surgery $57,74,82,103,106,132$ or ablative procedures,${ }^{86,132}$ an atypical component, ${ }^{82,118}$ appearance or aggravation of a sensory deficit, ${ }^{82}$ previous MVD,${ }^{66,75,120,133}$ age under 70 years, ${ }^{132}$ age under 60 years, ${ }^{112}$ distance between the isocenter and the exit of the nerve $>8 \mathrm{~mm},{ }^{112}$ and diabetes mellitus. ${ }^{83}$ Later pain relief maintenance following RS has been positively associated with new facial numbness ${ }^{63,106,118,132}$ and no past surgery 25 and negatively associated with a better initial response. ${ }^{118}$

The factors associated with hypesthesia onset and/or other complications have already been described.

\section{Particular Aspects}

Neurovascular Conflict and Its Effect on Pain Relief. The presence of a neurovascular conflict was found either to have no significance or to induce a favorable response. Additionally, a positive therapeutic response has been correlated with a higher dose to the point of contact between the impinging vessel and the nerve. Brisman et al..$^{14}$ studied 179 patients treated using RS, with 59\% presenting with a neurovascular conflict. These authors concluded that in cases without previous surgical treatment and with neurovascular conflict, the response to GKS was particularly favorable (BNI score I in $60 \%$ vs $31 \%$ with pain relief at the last follow-up, $\mathrm{p}=0.009)$. Erbay et al. ${ }^{30}$ analyzed $40 \mathrm{pa}-$ tients, 30 (75\%) of whom had a preoperative neurovascular conflict. Twenty-five (83.3\%) of the 30 patients had an adequate short-term response to GKS. The patients with a neurovascular conflict were 7 times more likely to have an adequate response to GKS than the patients without a neurovascular contact (OR 7.5).

In contrast, in the study by Shaya et al., ${ }^{120} 14$ (35\%) of 40 patients had a neurovascular conflict, and its presence did not significantly affect outcome $(p=0.6)$. Massager et al.$^{85}$ found no statistically significant relationship between the 3 subcategories of pain relief studied and the appearance of a neurovascular conflict on MRI. Sheehan et al. ${ }^{122}$ retrospectively analyzed 106 cases treated with GKS as a first-line treatment, using the REZ as a target and a mean maximal dose of 78.7 Gy (range 70-90 Gy). The median follow-up was 31 months. Sixty-three cases (59\%) had a neurovascular conflict. The authors concluded that there was no significant difference in pain relief between those with and those without vascular impingement after GKS $(p>0.05)$. Additionally, pain relief correlated with a higher dose to the point of contact between the impinging vessel and the nerve. 
A neurovascular conflict is not a negative predictor for RS (level II evidence).

Major Neurovascular Conflict by the Megadolichobasilar Artery and Its Effect on Pain Relief. Three studies addressed the issue of megadolichobasilar artery compression and its effect on the relief of pain. ${ }^{97,127,135}$ While Somaza et al. ${ }^{127}$ presented only a case report ( 2 shots of 4 and $8 \mathrm{~mm}$, gasserian ganglion target), the other 2 studies included $20^{97}$ and $29^{135}$ cases. The initial pain relief rate (BNI score I-IIIB) was high and varied between $75 \%$ and $100 \%$, with a low complication rate between $0 \%$ and $13 \%$. The recurrence rate ranged between $0 \%$ and $24.1 \%$. At 5 years, the FFP rate varied between $10 \%$ and $75.7 \%$. In their study, Park et al. ${ }^{97}$ concluded that there was no significant difference between patients with vertebrobasilar ectasia (VBE) and those without in terms of the rates of initial complete pain relief $(p=0.6)$, time to pain recurrence $(p=0.25)$, and postoperative sensory changes $(\mathrm{p}=0.73)$; however, longterm results at 5 years were better in the patients without $\operatorname{VBE}(42 \%$ vs $10 \%)$. In the series by Tuleasca et al., ${ }^{135}$ both initial pain relief and long-term pain control were better than in their general series, ${ }^{114}$ with a low complication rate. In selected cases, RS can be a safe and valuable alternative for this particular anatomical condition.

Focal Enhancement of the Fifth Cranial Nerve and/or Brainstem After RS. Alberico et al. ${ }^{2}$ studied the issue of focal enhancement of cranial nerve $\mathrm{V}$ after GKS in a cohort of 15 patients who had received doses ranging between 70 and $90 \mathrm{~Gy}$ and had undergone MRI within 5 months after the procedure. In 10 cases $(66.7 \%)$, radiosurgical target site enhancement was seen. All 5 patients with an unchanged trigeminal nerve radiological aspect had been treated with 70 Gy $(p=0.06)$. No correlation between enhancement and treatment response or time to follow-up was seen ( $p$ $>0.05$ ). Enhancement was seen as early as 32 days and as late as 188 days after treatment.

Friedman et al. ${ }^{38}$ evaluated radiological responses for 26 patients who had been treated with doses ranging between 70 and 90 Gy targeting either the REZ (21 patients) or the retrogasserian portion of the nerve (5 patients). Magnetic resonance imaging was performed at 3-6 months after RS in 21 patients. In 19 of these patients $(90.5 \%)$, no changes were identified in the trigeminal nerve or adjacent brainstem. The onset of a therapeutic effect ranged from 3 weeks to 3 months. In 2 cases with multiple sclerosis, abnormal signal and enhancement of the brainstem and/or trigeminal nerve was seen, without any clinical complications. The authors concluded that the results of enhanced MRI 3-6 months after RS do not correlate with clinical response.

Massager et al. studied a group of 78 patients treated with GKS for TN, 65 of whom had a 6-month MRI follow-up, which showed focal contrast enhancement of the trigeminal nerve. ${ }^{84}$ The authors coregistered the follow-up MRI studies with the radiosurgical planning MRI studies. Target accuracy was assessed from deviation of the coordinates of the intended target compared with the center of enhancement on postoperative MRI. The radiation dose delivered at the borders of contrast enhancement was also evaluated. The authors concluded that the median deviation in clinical assessment of GKS for TN was low and compatible with its high rate of efficiency. Furthermore, focal enhancement of the trigeminal nerve after RS occurred in $83 \%$ of their cases and was not associated with clinical outcome. Focal enhancement borders along the nerve root fit a median dose of $77 \pm 8.7 \mathrm{~Gy}$.

Gorgulho et al. ${ }^{40}$ showed that gadolinium enhancement of the brainstem at the REZ has a significant correlation with both pain relief and numbness $(\mathrm{p}=0.008$ and 0.02 , respectively) and that trigeminal nerve enhancement does not correlate with outcome. Better pain relief and a higher incidence of numbness are correlated to a higher radiation dose delivered to the REZ at the brainstem.

Impact of a Previous Surgical Procedure. Previous Versus No Previous Surgery: Retrospective Comparative Studies. Fountas et al. ${ }^{34}$ compared 2 groups, one without (52 patients) and one with (25 patients) previous surgeries. The 77-patient cohort was followed up over a period of 5 years and was treated with GKS using a median of 1 collimator (range 1-2 collimators), the REZ as the target, and a maximal median dose of 80 Gy (range 80-85 Gy), with the $30 \%$ isodose line adjacent to the REZ. In the group with no previous surgery, the initial response rate was $92.4 \%$ compared with $84 \%$ in the other group $(\mathrm{p}=0.16)$. The excellent outcome rates (FFP without medication) at 1,2 , and 3 years after treatment were $80.8 \%, 69.2 \%$, and $53.8 \%$ compared with $64 \%, 44 \%$, and $12 \%$, respectively ( $p=0.05$ at 2 years, $p=0.01$ at 3 years). The authors concluded that a previous surgical procedure is a negative predictor for long-term pain control after GKS treatment. The hypesthesia rates were similar, $17.3 \%$ in the group with no previous surgery and $16 \%$ in the other group $(\mathrm{p}=0.48)$. Two patients $(8 \%)$ in the group with previous surgery developed bothersome facial tingling.

The same authors conducted a study published the following year, ${ }^{35}$ which included 106 patients. They compared 2 groups without (57 patients) and with (49 patients) previous surgeries. The mean follow-up period was 34.3 months (range 12-72 months), and they used a median of 1 collimator (range 1-3 collimators), the REZ as the target, and a median maximal dose of 80 Gy (range 70-85 Gy). The initial response rate in those without previous surgery was $92.9 \%$ compared with $85.7 \%$ in the other group $(\mathrm{p}=$ 0.13 ). At 1 year after treatment, the FFP rates were $82.5 \%$ of those without previous surgery compared with $69.4 \%$ of those with, and the FFP rates were $78 \%$ and $63.5 \%$, respectively, at 2 years after treatment $(\mathrm{p}=0.27$ and 0.39 , respectively). The hypesthesia rate was similar, at $15.8 \%$ of patients without previous surgery and $16.3 \%$ of those with such surgery $(\mathrm{p}=0.73)$. Four cases ( 2 in each group) developed facial tingling and numbness.

Although not a comparative study itself, Dhople et al..$^{25}$ retrospectively analyzed 102 cases, which were separated into 2 groups according to a history of previous surgery or no such history. The difference in terms of actuarial pain relief at $1,2,3,4,5,6$, and 7 years, respectively, was as follows: $61 \%, 35 \%, 20 \%, 15 \%, 15 \%, 7 \%$, and $7 \%$ of those with a history of previous surgery compared with $81 \%, 53 \%$, $50 \%, 41 \%, 30 \%, 23 \%$, and $23 \%$ of those with no such history.

Previous surgery is a negative predictor for pain relief after RS; this factor does not, however, contraindicate RS (level II evidence). 


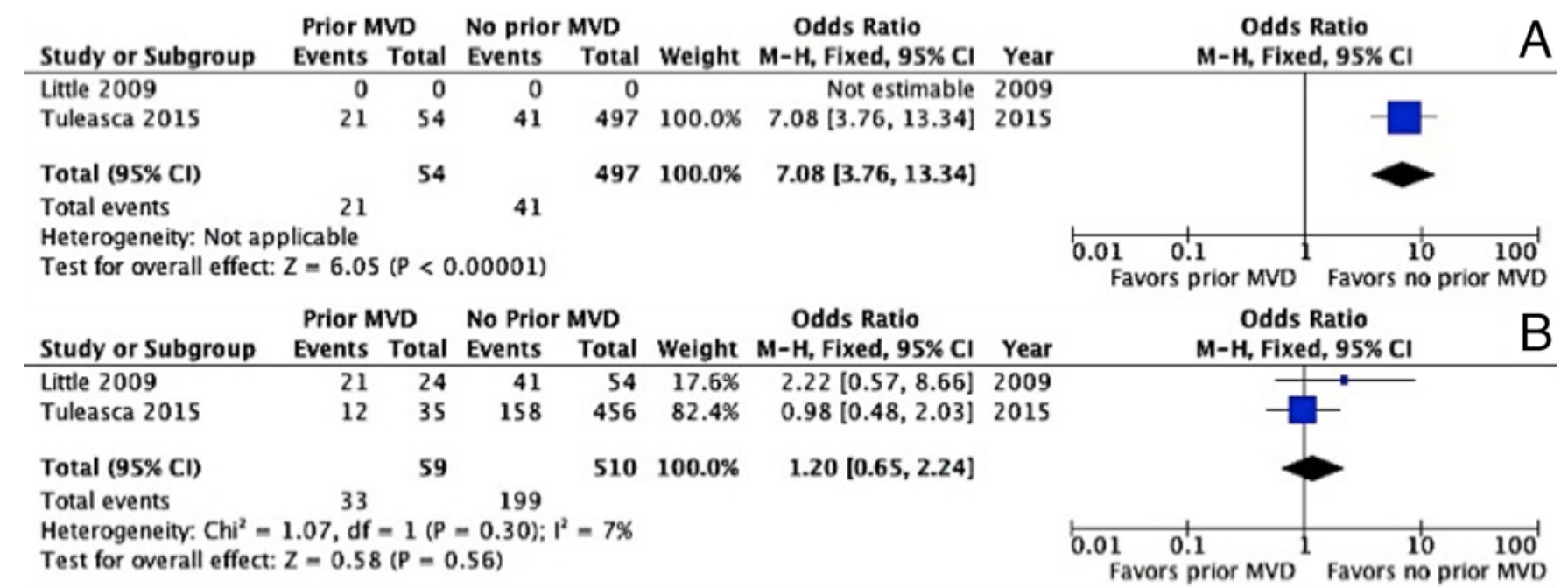

FIG. 5. When initial efficacy was pooled (A), there was a statistically significant difference between cases with prior MVD and those without, with an $\mathrm{HR}=7.08(95 \% \mathrm{Cl} 3.76,13.34), \mathrm{p}<0.00001$. For the maintenance of pain relief on a long-term basis $(\mathrm{B})$, there was no statistically significant difference, with an $\mathrm{HR}=1.20(95 \% \mathrm{Cl} 0.65,2.24), p=0.56$. Figure is available in color online only.

GKS After Previous Surgery: Retrospective Noncomparative Studies. Three other studies ${ }^{47,55,75}$ addressed the issue of GKS treatment as salvage therapy following a failed initial surgical procedure. Little et al. ${ }^{75}$ retrospectively evaluated 79 patients who had received a median dose of 80 Gy (range 70-90 Gy) and had a median followup of 5.3 years. The initial FFP response was $91 \%$, which is comparable to rates in general series. The actuarial pain relief rate at 5 years was $50 \%$, with FFP in $20 \%$ of patients. Seven patients $(10 \%)$ reported the development of facial numbness, and $8 \%$ described it as "very bothersome."

Huang et al. ${ }^{47}$ retrospectively evaluated 65 patients who had been treated with doses ranging between 70 and 90 Gy, a REZ target, and a unique 4-mm shot. The median follow-up was 64 months (range 18-32 months). The authors compared 3 different treatment groups: initial MVD and further GKS, initial GKS and further GKS, and initial percutaneous RFT and further GKS. There was no significant difference in terms of FFP: $74 \%$ versus $59 \%$ and $50 \%$, respectively $(\mathrm{p}=0.342)$. The overall recurrence rate was $35.4 \%$, and recurrence appeared after a median time of 7 months (range 3-48 months). There was no significant difference in new facial numbness among the 3 treatment groups $(\mathrm{p}=0.24)$. The FFP actuarial rates at 1,2 , and 3 years after treatment were $74 \%, 71 \%$, and $66 \%$ of the patients, respectively.

Kano et al.$^{55}$ retrospectively reviewed 193 patients with TN treated with GKS after one or more previously failed surgeries. The median dose was 80 Gy (range 60-90 Gy), and the maximum follow-up was 14 years. After GKS, $85 \%$ of the patients achieved pain relief or improvement (BNI score I-IIIB). Pain recurrence was observed in $43.5 \%$ of the cases after a median of 72 months (range 6-144 months). Eighteen cases (9.3\%) developed facial numbness (new or increased) and 1 case $(0.5 \%)$ developed deafferentation pain.

GKS After Previous MVD. Two retrospective studies address the issue of GKS following MVD ${ }^{75,133}$ Little et al. ${ }^{75}$ made an analysis of a subgroup of 24 patients treated with GKS after a previous MVD. The authors stated that at 5 years, only $12 \%$ of patients with prior MVD had FFP compared with $25 \%$ who had no history of MVD $(\mathrm{p}=0.029)$. Tuleasca et al. ${ }^{133}$ compared 54 prior-MVD cases with a cohort of 497 cases with more than 1 year of follow-up (range 14.1-144.6 months). The patients were treated at a retrogasserian target with a median dose of 85 Gy (range 70-90 Gy). Although not a case-control study, the authors found that patients with previous MVD had a significantly lower probability of initial pain cessation $(77.8 \%$ vs $91.75 \%, p=0.01)$. However, the probability of maintaining pain relief without medication was $44.3 \%$ at 10 years, similar to the rate in the larger cohort $(45.3 \%$, $\mathrm{p}=0.85$ ). Toxicity was low, with an actuarial hypesthesia rate of only $9.1 \%$ in the patients with prior MVD (BNI score II).

Figure 5 shows a comparison of cases with versus those without prior MVD. When initial efficacy was pooled, there was a statistically significant difference between the two, with an HR $=7.08$ (95\% CI 3.76, 13.34), p < 0.00001 (Fig. 5A). For the maintenance of pain relief on a longterm basis, there was no statistically significant difference between the cases with and those without prior MVD, with an $\mathrm{HR}=1.20$ (95\% CI 0.65, 2.24), $\mathrm{p}=0.56$ (Fig. 5B)

Particular Follow-Up Aspects: The Risk of Vascular Damage After RS. Lorenzoni et al. ${ }^{78}$ prospectively evaluated the maximal dose received by the SCA. In 55 patients treated with GKS for classical TN, who received a dose of 15 Gy or more to the SCA, and who had a minimum follow-up of 1 year, the study end points were SCA occlusion, stenosis, or infarction in the supplied territory. Fifteen patients whose SCA had received a mean maximal dose of 57.5 Gy (range 15-87 Gy) were ultimately analyzed. Neither obstruction nor infarction was demonstrated. In 1 patient, asymptomatic SCA stenosis, which was visualized distant to the irradiation field, was suspected. The authors concluded that the SCA could receive a high dose of radia- 
tion during radiosurgical treatment, with no confirmation of any vascular damage induced by RS.

Yatshushiro et al. ${ }^{143}$ reported a case of SCA occlusion with cerebellar infarction 15 months after GKS in a 55-year-old patient, with a dose between 65 and 75 Gy received by the artery.

Other cases that are not related to targeting of the trigeminal nerve in classical TN are not discussed here.

Quality of Life and Patient Satisfaction. Petit et al. ${ }^{103}$ reported a median of $80 \%$ improvement in QOL after GKS, as a direct result of pain relief, and $65 \%$ of the patients believed that GKS was successful in their case. Patients in whom pain relief was maintained at the time of analysis reported a median 100\% improvement in their QOL, with a $100 \%$ success rate. Those with temporary treatment responses (pain recurrence after a median of 8.5 months) described a median of $80 \%$ improvement in QOL with an associated $60 \%$ rate of treatment success. Jawahar et al. ${ }^{51}$ showed that patients' self-reported QOL scores improved $90 \%$ and that overall patient satisfaction was $80 \%$. Régis et al. studied QOL for 100 patients treated with GKS and followed up prospectively. ${ }^{112}$ The authors concluded that all QOL parameters were improved after RS ( $\mathrm{p}<0.001)$.

Azar et al. ${ }^{9}$ compared QOL before and after GKS, stating that statistically significant positive changes were encountered in all domains, except in physical function and in role limitation due to a physical problem. Pan et al. ${ }^{95}$ evaluated QOL in 52 patients who were severely ill (BNI score IV or V) at baseline and were subsequently treated with GKS. The mean physical function score was $55.9 \pm$ 7.7 before GKS and improved to a mean of $66.3 \pm 8.1$ at 3 months after GKS. The mean score for role limitation due to an emotional problem changed from $4.8 \pm 9.9$ at the time of GKS to $86.5 \pm 12.6$ at 3 months after GKS. The mean social functioning score changed from $32.0 \pm 5.7$ to $80.3 \pm 8.7$.

In the series by Régis et al., ${ }^{115} 93.1 \%$ of the patients had no regrets and said they would undergo RS again without hesitation, whereas $4.6 \%$ regretted having undergone the procedure and would not undergo it again.

\section{Cost-Effectiveness Analysis}

The cost-effectiveness analysis of TN surgery in general has been addressed in 5 studies. ${ }^{37,46,105,123,131}$ Pollock et al. ${ }^{105}$ included 126 patients who underwent 153 interventions (33 MVD, 51 glycerol injection [GLR], 69 RS) and had a mean follow-up of 20.6 months. A higher percentage of patients who underwent MVD obtained and maintained excellent outcomes, compared with the patients who underwent GLR and RS (78\% vs 55\% and 52\%, respectively, at 2 years; $\mathrm{p}=0.01$ for both). The authors concluded that the use of percutaneous procedures in older patients is supported by the results. Additionally, if the risk of general anesthesia is acceptable, MVD should be the preferred operation.

Tarricone et al. ${ }^{131}$ evaluated 20 patients undergoing CKR and 20 undergoing MVD, both groups including only patients with a BNI score of IV or V at baseline. The 2 procedures were equally effective at 6 months' followup but had different resources consumption: CKR reduced hospital costs by an average of $34 \%$ per patient. The au- thors concluded that CKR is the cost-saving alternative to MVD.

Fransen $^{37}$ compared MVD to RFT, BMC, and GKS. This author concluded that percutaneous techniques are more cost-effective than GKS.

Sivakanthan et al. ${ }^{123}$ evaluated the use and cost-effectiveness of 3 different surgical procedures by using the Medicare Claims database. A total number of 1582 claims were collected. In patients undergoing surgery, $51.1 \%$ underwent MVD, $41.5 \%$ RS, and 7.4\% RFT. These authors concluded that the most frequently used surgical treatment was MVD, followed closely by stereotactic RS, and that RFT, despite being the most cost-effective, is the least used treatment modality.

Holland et al. ${ }^{46}$ retrospectively analyzed a cohort of 89 patients who had undergone MVD (27 patients), RFT (23 patients), and RS (39 patients). At baseline, the patients significantly differed by age (mean 53.9 years vs 76.2 and 74.5 years, $\mathrm{p}<0.001$, MVD vs RFT and RS groups). Facial numbness significantly differed between the groups: $11 \%$, $52 \%$, and $28 \%$, respectively $(\mathrm{p}<0.01)$. At 2 years, the rates of recurrence requiring a new procedure were $22 \%$ compared with $74 \%$ and $31 \%(\mathrm{p}<0.01)$ in a mean time of $26 \pm$ $29,59 \pm 76$, and $35 \pm 25$ months, respectively. The authors concluded that MVD was the most expensive procedure, was performed in younger patients, and had the lowest rate of facial numbness and recurrence. Radiosurgery was slightly less costly, was more likely to be performed in older patients, and had a short-term recurrence rate similar to that for MVD. Radiofrequency rhizotomy was the least expensive with immediate pain relief but the highest rates of facial numbness and recurrence.

\section{MVD Versus RS: Comparative Studies}

The only prospective, nonrandomized cohort trial comparing MVD and GKS (dose 80-90 Gy, target REZ, brainstem receiving a maximum of 16 Gy at the $20 \%$ isodose line) was performed by Linskey et al., ${ }^{73}$ with outcomes reported for 80 patients (36 treated with MVD, 44 with GKS). Over a mean follow-up of $3.4 \pm 2.14$ years (range 0.17-8.5 years), the initial and last follow-up FFP rates were $100 \%$ and $80.6 \%$ for the MVD group and $77.3 \%$ and $45.5 \%$ for the GKS group, respectively. The respective actuarial FFP rates initially and at 2 and 5 years' follow-up were $100 \%, 88 \%$, and $80 \%$ for the MVD group compared with $78 \%, 50 \%$, and $33 \%$ for the GKS group (p $=0.0002)$. The permanent mild and severe sensory loss rates were $5.6 \%$ and $0 \%$ in the MVD group compared with $6.8 \%$ and $2.3 \%$ in the GKS group. Complications such as CSF leakage, hearing loss, and persistent diplopia (1 case each) were found only in the MVD group. The authors concluded that MVD should be preferred as the first-line surgical therapy in young and healthy patients, whereas GKS should be performed in those who are older, have significant medical problems, or refuse the recommended intervention of MVD.

In the framework of a retrospective study, Pollock compared patients (age $<70$ years) who had undergone posterior fossa exploration (PFE; 55 patients) with those who had undergone GKS (28 patients). ${ }^{104}$ At a mean followup of 25.5 months, PFE cases more commonly had FFP 


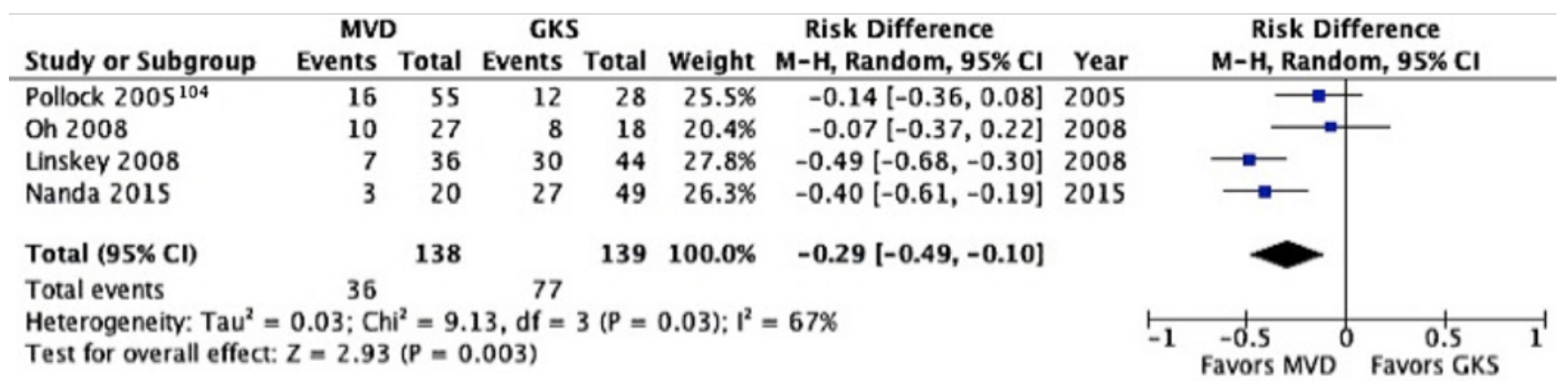

FIG. 6. When the maintenance of pain relief on a long-term basis was compared between MVD and GKS, there was a statistically significant difference, with an $\mathrm{HR}=-0.29(95 \% \mathrm{Cl}-0.49,-0.10), p=0.003$. Figure is available in color online only.

without medication (75\% at 1 year and $72 \%$ at 3 years vs $59 \%$ at both 1 and 3 years, $\mathrm{p}=0.01$ ). New facial numbness or dysesthesias appeared in $15 \%$ of the patients after PPE compared with $43 \%$ after GKS (REZ target and mean maximum dose of $89.1 \mathrm{~Gy}, \mathrm{p}=0.02$ ).

Oh et al. ${ }^{94}$ retrospectively evaluated older patients (age $>65$ years) treated with MVD (27 patients) versus GKS (18 patients, target REZ, mean dose 77.8 Gy [range 7084.3 Gy], one 4-mm collimator). At a mean follow-up of 35.9 months for the MVD group and 33.1 months for the GKS group, according to the BNI pain intensity scale, a better prognosis (63\% vs $55.6 \%$ with score I or II) and an earlier response was found in the MVD group, with an identical recurrence rate in the 2 groups. Lower complication rates were seen in the GKS group, with only 1 case of dysesthesia (5.6\%) compared with 2 cases of facial numbness and 1 case each of herpes zoster, CSF leakage, hearing disturbance, and subdural hematoma in the MVD group.

Nanda et al..$^{92}$ retrospectively reviewed 20 patients treat- ed with MVD and 49 treated with GKS, with no prior or further intervention and a median follow-up of 5.3 years. The authors concluded that there was no significant difference in terms of initial pain relief $(100 \%$ MVD and $84 \%$ GKS, $\mathrm{p}=0.055)$ or in recurrence $(20 \%$ MVD and $39 \%$ GKS, $p=0.133$ ). At the last follow-up, $85 \%$ of MVD cases had a BNI score of I compared with $45 \%$ of the GKS cases $(p=0.002)$. Patient satisfaction was the same in the 2 groups. However, this study lacks details about the technical nuances regarding GKS.

Figure 6 shows results of a comparison of MVD versus GKS. For the maintenance of pain relief on a long-term basis, there was a statistically significant difference, with an $\mathrm{HR}=-0.29(95 \% \mathrm{CI}-0.49,-0.10), \mathrm{p}=0.003$.

However, the results previously described should be balanced with several factors, including the overall risk of complications. Microvascular decompression yields more risks than RS, including severe facial numbness $(1.8 \%)$ or major complications such as chemical meningitis (19\%), cerebrospinal fluid leakage (1.7\%), ipsilateral hearing loss

TABLE 5. Final recommendations

\begin{tabular}{ll}
$\begin{array}{c}\text { Evidence } \\
\text { Level }\end{array}$ & \multicolumn{1}{c}{ Recommendation } \\
\hline II & Single-fraction RS is better than hypofractionated RS \\
\hline II & Previous surgery is a negative predictor for pain relief after RS; this factor does not, however, contraindicate RS \\
\hline II & A neurovascular conflict is not a negative predictor for RS \\
\hline II \& II & The minimal effective dose is 70 Gy \\
& $\begin{array}{l}\text { Do not increase the length of the treated nerve: use only one 4-mm isocenter; using } 2 \text { isocenters (either continuously or concentrically) } \\
\text { yields similar rates of initial efficacy but w/ increased toxicity (so-called Flickinger effect); do not use beam channel blocking at } 90 \text { Gy }\end{array}$ \\
\hline II & An anterior target \& a posterior target have similar initial efficacy \\
\hline II & An anterior target has lower hypesthesia \& bothersome hypesthesia rates than the posterior target \\
\hline II \& III & Additional complications, including dry eye syndrome, are seen only w/ a posterior target \\
\hline III & SR anterior target, as compared to the posterior one, has higher pain relief rates on a long-term basis (7 \& 10 yrs' FU) \\
\hline III & SRS yields a better initial freedom from pain response if performed in the first 3 years after pain onset \\
\hline III & The maximal effective dose is 90 Gy \\
\hline III & Beyond 90 Gy, the efficacy rate remains similar but w/ a higher complication rate \\
\hline III & LINAC \& CKR result in higher bothersome hypesthesia rates \\
\hline
\end{tabular}

Anterior target = placement of a unique 4-mm shot on the cisternal portion of the trigeminal nerve, at approximately $7-8 \mathrm{~mm}$ from its emergence from the brainstem; FU $=$ follow-up; posterior target $=$ placement of a unique $4-\mathrm{mm}$ shot at the emergence of the nerve. 
(1.3\%), extraocular muscle palsy (1.2\%), facial palsy (1\%), and a very low postoperative death rate $(0.2 \%){ }^{11}$

Microvascular decompression is the reference technique, whereas SRS can be recommended as an alternative (level III evidence).

\section{Percutaneous Procedures}

Percutaneous techniques are ablative as they act by causing destruction of the nerve fibers via thermal energy (RFT), chemical damage (glycerol rhizotomy), or mechanical damage (BMC). Within this framework, they frequently cause facial numbness of variable grades as a condition of complete and sustained efficacy. Initial pain relief rates range between $90 \%$ and $97.6 \%$ for all of these techniques, and at 3 years the pain relief rate falls to between $53 \%$ and $69 \%$, with severe numbness occurring in up to $20 \%-23 \%$ of patients. These procedures are notable for high recurrence rates (as high as $26 \%$ at a very short mean time of 18 months). ${ }^{16,20,56,93}$ Additionally, other procedure-related complications include exposure keratitis $(0 \%-2 \%)$, anesthesia dolorosa $(0 \%-2.5 \%)$, troublesome dysesthesias $(4 \%-10 \%)$, and masticatory weakness $(0-12 \%){ }^{16,20,56,93}$

\section{Quality of Reporting}

Since 2003, Zakrzewska et al. have proposed a protocol for collecting data and reporting on surgical treatment for TN. ${ }^{22,147}$ The only RS paper that completely (with the exception of the follow-up period) fulfills such a practice remains the one written by Régis et al. ${ }^{12}$ We believe that in future papers, for easier and more standardized comparison of the results, one should follow such recommendations.

\section{Conclusions}

Radiosurgery for TN is currently considered a minimally invasive alternative to the standard MVD. Technical refinements over time have aimed at improving the safety and efficacy of RS. The availability of MRI at the beginning of the 1990s largely contributed to the appraisal of this indication due to the direct and better visualization of the trigeminal nerve. Upfront radiosurgical treatment should be performed in cases with pharmacoresistance during the first 3 years after diagnosis. Although RS has lower pain relief rates on a long-term basis, careful and individual analysis should be made and the risks of both interventions should be balanced with a patient's age, anatomical condition, and potential benefit. While most analyzed series use the posterior target, comparative studies have demonstrated that the anterior retrogasserian target yields similar initial pain relief rates with a lower probability of toxicity (as well as a lower probability of bothersome and very bothersome hypesthesia) and higher maintenance of the FFP response on a long-term basis.

Although there is only one level I study (Flickinger et al..$^{32}$ ) and the rest of the studies comprise level II evidence, to help guide the management of patients with classical $\mathrm{TN}$ and given the limitations of the retrospective series, a number of consensus statements have been made (Table 5).

\section{References}

1. Adler JR Jr, Bower R, Gupta G, Lim M, Efron A, Gibbs IC, et al: Nonisocentric radiosurgical rhizotomy for trigeminal neuralgia. Neurosurgery 64 (2 Suppl):A84-A90, 2009

2. Alberico RA, Fenstermaker RA, Lobel J: Focal enhancement of cranial nerve $\mathrm{V}$ after radiosurgery with the Leksell gamma knife: experience in 15 patients with medically refractory trigeminal neuralgia. AJNR Am J Neuroradiol 22:1944-1948, 2001

3. Alexander E, Loeffler JS, Lunsford DL (eds): Stereotactic Radiosurgery. New York: McGraw-Hill, 1993, Vol 1

4. Alpert TE, Chung CT, Mitchell LT, Hodge CJ, Montgomery CT, Bogart JA, et al: Gamma knife surgery for trigeminal neuralgia: improved initial response with two isocenters and increasing dose. J Neurosurg 102 Suppl:185-188, 2005

5. André N: Observations pratiques sur les maladies de l'urethre. Paris: Delaguette, 1756

6. Arai Y, Kano H, Lunsford LD, Novotny J Jr, Niranjan A, Flickinger JC, et al: Does the Gamma Knife dose rate affect outcomes in radiosurgery for trigeminal neuralgia? J Neurosurg 113 Suppl:168-171, 2010

7. Attia A, Tatter SB, Weller M, Marshall K, Lovato JF, Bourland JD, et al: CT-only planning for Gamma Knife radiosurgery in the treatment of trigeminal neuralgia: methodology and outcomes from a single institution. J Med Imaging Radiat Oncol 56:490-494, 2012

8. Aykol Ş, Börcek AÖ, Emmez H, Öcal Ö, Paşaoğlu A: Results of radiosurgery for trigeminal neuralgia: Ankara experience. Br J Neurosurg 29:54-58, 2014

9. Azar M, Yahyavi ST, Bitaraf MA, Gazik FK, Allahverdi M, Shahbazi S, et al: Gamma knife radiosurgery in patients with trigeminal neuralgia: quality of life, outcomes, and complications. Clin Neurol Neurosurg 111:174-178, 2009

10. Balamucki CJ, Stieber VW, Ellis TL, Tatter SB, Deguzman $\mathrm{AF}$, McMullen KP, et al: Does dose rate affect efficacy? The outcomes of 256 Gamma Knife surgery procedures for trigeminal neuralgia and other types of facial pain as they relate to the half-life of cobalt. J Neurosurg 105:730-735, 2006

11. Barker FG II, Jannetta PJ, Bissonette DJ, Larkins MV, Jho HD: The long-term outcome of microvascular decompression for trigeminal neuralgia. N Engl J Med 334:1077-1083, 1996

12. Borchers JD III, Yang HJ, Sakamoto GT, Howes GA, Gupta G, Chang SD, et al: Cyberknife stereotactic radiosurgical rhizotomy for trigeminal neuralgia: anatomic and morphological considerations. Neurosurgery 64 (2 Suppl):A91-A95, 2009

13. Brisman R: Gamma knife radiosurgery for primary management for trigeminal neuralgia. J Neurosurg 93 (Suppl 3): $159-161,2000$

14. Brisman R, Khandji AG, Mooij RB: Trigeminal nerve-blood vessel relationship as revealed by high-resolution magnetic resonance imaging and its effect on pain relief after gamma knife radiosurgery for trigeminal neuralgia. Neurosurgery 50:1261-1267, 2002

15. Brisman R, Mooij R: Gamma knife radiosurgery for trigeminal neuralgia: dose-volume histograms of the brainstem and trigeminal nerve. J Neurosurg 93 (Suppl 3): 155-158, 2000

16. Brown JA, McDaniel MD, Weaver MT: Percutaneous trigeminal nerve compression for treatment of trigeminal neuralgia: results in 50 patients. Neurosurgery 32:570-573, 1993

17. Chang JW, Chang JH, Park YG, Chung SS: Gamma knife radiosurgery for idiopathic and secondary trigeminal neuralgia. J Neurosurg 93 (Suppl 3): 147-151, 2000

18. Chen JC, Girvigian M, Greathouse H, Miller M, Rahimian $\mathrm{J}$ : Treatment of trigeminal neuralgia with linear accelerator radiosurgery: initial results. J Neurosurg 101 (Suppl 3):346350,2004

19. Chen JC, Rahimian J, Rahimian R, Arrelano A, Miller 
MJ, Girvigian MR: Frameless image-guided radiosurgery for initial treatment of typical trigeminal neuralgia. World Neurosurg 75:538-543, 2010

20. Cheng JS, Lim DA, Chang EF, Barbaro NM: A review of percutaneous treatments for trigeminal neuralgia. Neurosurgery [epub ahead of print], 2013

21. Cheuk AV, Chin LS, Petit JH, Herman JM, Fang HB, Regine WF: Gamma knife surgery for trigeminal neuralgia: outcome, imaging, and brainstem correlates. Int J Radiat Oncol Biol Phys 60:537-541, 2004

22. Cruccu G, Finnerup NB, Jensen TS, Scholz J, Sindou M, Svensson P, et al: Trigeminal neuralgia: new classification and diagnostic grading for practice and research. Neurology 87:220-228, 2016

23. Dandy W: Concerning the cause of trigeminal neuralgia. Am J Surg 24:447-455, 1934

24. Dellaretti M, Reyns N, Touzet G, Sarrazin T, Dubois F, Lartigau E, et al: Clinical outcomes after Gamma Knife surgery for idiopathic trigeminal neuralgia: review of 76 consecutive cases. J Neurosurg 109 Suppl:173-178, 2008

25. Dhople AA, Adams JR, Maggio WW, Naqvi SA, Regine WF, Kwok Y: Long-term outcomes of Gamma Knife radiosurgery for classic trigeminal neuralgia: implications of treatment and critical review of the literature. Clinical article. $\mathbf{J}$ Neurosurg 111:351-358, 2009

26. Dos Santos MA, Pérez de Salcedo JB, Gutiérrez Diaz JA, Nagore G, Calvo FA, Samblás J, et al: Outcome for patients with essential trigeminal neuralgia treated with linear accelerator stereotactic radiosurgery. Stereotact Funct Neurosurg 89:220-225, 2011

27. Drzymala RE, Malyapa RS, Dowling JL, Rich KM, Simpson JR, Mansur DB: Gamma knife radiosurgery for trigeminal neuralgia: the Washington University initial experience. Stereotact Funct Neurosurg 83:148-152, 2005

28. Elaimy AL, Hanson PW, Lamoreaux WT, Mackay AR, Demakas JJ, Fairbanks RK, et al: Clinical outcomes of gamma knife radiosurgery in the treatment of patients with trigeminal neuralgia. Int J Otolaryngol 2012:919186, 2012

29. Eller JL, Raslan AM, Burchiel KJ: Trigeminal neuralgia: definition and classification. Neurosurg Focus 18(5):E3, 2005

30. Erbay SH, Bhadelia RA, Riesenburger R, Gupta P, O'Callaghan M, Yun E, et al: Association between neurovascular contact on MRI and response to gamma knife radiosurgery in trigeminal neuralgia. Neuroradiology 48:26-30, 2006

31. Fariselli L, Marras C, De Santis M, Marchetti M, Milanesi I, Broggi G: CyberKnife radiosurgery as a first treatment for idiopathic trigeminal neuralgia. Neurosurgery 64 (2 Suppl):A96-A101, 2009

32. Flickinger JC, Pollock BE, Kondziolka D, Phuong LK, Foote RL, Stafford SL, et al: Does increased nerve length within the treatment volume improve trigeminal neuralgia radiosurgery? A prospective double-blind, randomized study. Int J Radiat Oncol Biol Phys 51:449-454, 2001

33. Flickinger JC Jr, Kim H, Kano H, Greenberger JS, Arai Y, Niranjan A, et al: Do carbamazepine, gabapentin, or other anticonvulsants exert sufficient radioprotective effects to alter responses from trigeminal neuralgia radiosurgery? Int $\mathbf{J}$ Radiat Oncol Biol Phys 83:e501-e506, 2012

34. Fountas KN, Lee GP, Smith JR: Outcome of patients undergoing gamma knife stereotactic radiosurgery for medically refractory idiopathic trigeminal neuralgia: Medical College of Georgia's experience. Stereotact Funct Neurosurg 84:8896, 2006

35. Fountas KN, Smith JR, Lee GP, Jenkins PD, Cantrell RR, Sheils WC: Gamma Knife stereotactic radiosurgical treatment of idiopathic trigeminal neuralgia: long-term outcome and complications. Neurosurg Focus 23(6):E8, 2007

36. Fraioli MF, Strigari L, Fraioli C, Lecce M, Lisciani D:
Preliminary results of 45 patients with trigeminal neuralgia treated with radiosurgery compared to hypofractionated stereotactic radiotherapy, using a dedicated linear accelerator. J Clin Neurosci 19:1401-1403, 2012

37. Fransen P: Cost-effectiveness in the surgical treatments for trigeminal neuralgia. Acta Neurol Belg 112:245-247, 2012

38. Friedman DP, Morales RE, Goldman HW: Role of enhanced MRI in the follow-up of patients with medically refractory trigeminal neuralgia undergoing stereotactic radiosurgery using the gamma knife: initial experience. J Comput Assist Tomogr 25:727-732, 2001

39. Frighetto L, De Salles AA, Smith ZA, Goss B, Selch M, Solberg T: Noninvasive linear accelerator radiosurgery as the primary treatment for trigeminal neuralgia. Neurology 62:660-662, 2004

40. Gorgulho A, De Salles AA, McArthur D, Agazaryan N, Medin P, Solberg T, et al: Brainstem and trigeminal nerve changes after radiosurgery for trigeminal pain. Surg Neurol 66: $127-135,2006$

41. Gorgulho AA, De Salles AA: Impact of radiosurgery on the surgical treatment of trigeminal neuralgia. Surg Neurol 66:350-356, 2006

42. Goss BW, Frighetto L, DeSalles AA, Smith Z, Solberg T, Selch M: Linear accelerator radiosurgery using 90 gray for essential trigeminal neuralgia: results and dose volume histogram analysis. Neurosurgery 53:823-830, 2003

43. Han JH, Kim DG, Chung HT, Paek SH, Kim YH, Kim CY, et al: Long-term outcome of gamma knife radiosurgery for treatment of typical trigeminal neuralgia. Int J Radiat Oncol Biol Phys 75:822-827, 2009

44. Hayashi M, Chernov M, Tamura N, Taira T, Izawa M, Yomo $\mathrm{S}$, et al: Stereotactic radiosurgery of essential trigeminal neuralgia using Leksell Gamma Knife model C with automatic positioning system: technical nuances and evaluation of outcome in 130 patients with at least 2 years follow-up after treatment. Neurosurg Rev 34:497-508, 2011

45. Headache Classification Committee of the International Headache Society (IHS): The International Classification of Headache Disorders, 3rd edition (beta version). Cephalalgia Int J Headache 33:629-808, 2013

46. Holland M, Noeller J, Buatti J, He W, Shivapour ET, Hitchon PW: The cost-effectiveness of surgery for trigeminal neuralgia in surgically naïve patients: a retrospective study. Clin Neurol Neurosurg 137:34-37, 2015

47. Huang CF, Chiou SY, Wu MF, Tu HT, Liu WS: Gamma Knife surgery for recurrent or residual trigeminal neuralgia after a failed initial procedure. J Neurosurg 113 Suppl:172177,2010

48. Huang CF, Tu HT, Liu WS, Lin LY: Gamma Knife surgery for trigeminal pain caused by benign brain tumors. $\mathbf{J}$ Neurosurg 109 Suppl:154-159, 2008

49. Huang CF, Tu HT, Liu WS, Lin LY: Gamma Knife surgery used as primary and repeated treatment for idiopathic trigeminal neuralgia. J Neurosurg 109 Suppl:179-184, 2008

50. Jannetta PJ: Microsurgical management of trigeminal neuralgia. Arch Neurol 42:800, 1985

51. Jawahar A, Wadhwa R, Berk C, Caldito G, DeLaune A, Ampil F, et al: Assessment of pain control, quality of life, and predictors of success after gamma knife surgery for the treatment of trigeminal neuralgia. Neurosurg Focus 18(5):E8, 2005

52. Jorns TP, Zakrzewska JM: Evidence-based approach to the medical management of trigeminal neuralgia. $\mathbf{B r} \mathbf{J}$ Neurosurg 21:253-261, 2007

53. Kannan V, Deopujari CE, Misra BK, Shetty PG, Shroff MM, Pendse AM: Gamma-knife radiosurgery for trigeminal neuralgia. Australas Radiol 43:339-341, 1999

54. Kanner AA, Neyman G, Suh JH, Weinhous MS, Lee SY, Barnett GH: Gamma knife radiosurgery for trigeminal neu- 
ralgia: comparing the use of a 4-mm versus concentric 4- and 8-mm collimators. Stereotact Funct Neurosurg 82:49-57, 2004

55. Kano H, Kondziolka D, Yang HC, Zorro O, Lobato-Polo J, Flannery TJ, et al: Outcome predictors after gamma knife radiosurgery for recurrent trigeminal neuralgia. Neurosurgery 67:1637-1645, 2010

56. Kanpolat Y, Savas A, Bekar A, Berk C: Percutaneous controlled radiofrequency trigeminal rhizotomy for the treatment of idiopathic trigeminal neuralgia: 25-year experience with 1,600 patients. Neurosurgery 48:524-534, 2001

57. Karam SD, Tai A, Wooster M, Rashid A, Chen R, Baig N, et al: Trigeminal neuralgia treatment outcomes following Gamma Knife radiosurgery with a minimum 3-year followup. J Radiat Oncol 3:125-130, 2014

58. Kim YH, Kim DG, Kim JW, Kim YH, Han JH, Chung HT, et al: Is it effective to raise the irradiation dose from 80 to 85 Gy in gamma knife radiosurgery for trigeminal neuralgia? Stereotact Funct Neurosurg 88:169-176, 2010

59. Kondziolka D, Flickinger JC, Lunsford LD, Habeck M: Trigeminal neuralgia radiosurgery: the University of Pittsburgh experience. Stereotact Funct Neurosurg 66 (Suppl 1):343-348, 1996

60. Kondziolka D, Lacomis D, Niranjan A, Mori Y, Maesawa S, Fellows W, et al: Histological effects of trigeminal nerve radiosurgery in a primate model: implications for trigeminal neuralgia radiosurgery. Neurosurgery 46:971-977, 2000

61. Kondziolka D, Lunsford LD, Flickinger JC, Young RF, Vermeulen S, Duma CM, et al: Stereotactic radiosurgery for trigeminal neuralgia: a multiinstitutional study using the gamma unit. J Neurosurg 84:940-945, 1996

62. Kondziolka D, Perez B, Flickinger JC, Habeck M, Lunsford LD: Gamma knife radiosurgery for trigeminal neuralgia: results and expectations. Arch Neurol 55:1524-1529, 1998

63. Kondziolka D, Zorro O, Lobato-Polo J, Kano H, Flannery TJ, Flickinger JC, et al: Gamma Knife stereotactic radiosurgery for idiopathic trigeminal neuralgia. J Neurosurg 112:758765,2010

64. Kubicek GJ, Hall WA, Orner JB, Gerbi BJ, Dusenbery KE: Long-term follow-up of trigeminal neuralgia treatment using a linear accelerator. Stererotact Funct Neurosurg 82:244249,2004

65. Lazzara BM, Ortiz O, Bordia R, Witten MR, Haas JA, Katz $\mathrm{AJ}$, et al: Cyberknife radiosurgery in treating trigeminal neuralgia. J Neurointerv Surg 5:81-85, 2013

66. Lee JK, Choi HJ, Ko HC, Choi SK, Lim YJ: Long term outcomes of gamma knife radiosurgery for typical trigeminal neuralgia-minimum 5-year follow-up. J Korean Neurosurg Soc 51:276-280, 2012

67. Lee JK, Kim DR, Huh YH, Kim JK, Namgung WC, Hong SH: Long-term outcome of gamma knife surgery using a retrogasserian petrous bone target for classic trigeminal neuralgia. Acta Neurochir Suppl 116:127-135, 2013

68. Lee JY, Sandhu S, Miller D, Solberg T, Dorsey JF, AlonsoBasanta M: Higher dose rate Gamma Knife radiosurgery may provide earlier and longer-lasting pain relief for patients with trigeminal neuralgia. J Neurosurg 123:961-968, 2015

69. Leksell L: The stereotaxic method and radiosurgery of the brain. Acta Chir Scand 102:316-319, 1951

70. Liang CL, Ho MW, Lu K, Tsai YD, Liliang PC, Wang KW, et al: An investigation of eye lens dose of stereotactic radiosurgery for trigeminal neuralgia using Leksell Gamma Knife model C. J Neurosurg 105 Suppl:112-116, 2006

71. Lim M, Cotrutz C, Romanelli P, Schaal D, Gibbs I, Chang $\mathrm{SD}$, et al: Stereotactic radiosurgery using CT cisternography and non-isocentric planning for the treatment of trigeminal neuralgia. Comput Aided Surg 11:11-20, 2006

72. Lim M, Villavicencio AT, Burneikiene S, Chang SD, Romanelli P, McNeely L, et al: CyberKnife radiosurgery for idiopathic trigeminal neuralgia. Neurosurg Focus 18(5):E9, 2005

73. Linskey ME, Ratanatharathorn V, Peñagaricano J: A prospective cohort study of microvascular decompression and Gamma Knife surgery in patients with trigeminal neuralgia. J Neurosurg 109 Suppl:160-172, 2008

74. Little AS, Shetter AG, Shetter ME, Bay C, Rogers CL: Longterm pain response and quality of life in patients with typical trigeminal neuralgia treated with gamma knife stereotactic radiosurgery. Neurosurgery 63:915-924, 2008

75. Little AS, Shetter AG, Shetter ME, Kakarla UK, Rogers CL: Salvage gamma knife stereotactic radiosurgery for surgically refractory trigeminal neuralgia. Int J Radiat Oncol Biol Phys 74:522-527, 2009

76. Loescher AR, Radatz M, Kemeny A, Rowe J: Stereotactic radiosurgery for trigeminal neuralgia: outcomes and complications. Br J Neurosurg 26:45-52, 2012

77. Longhi M, Rizzo P, Nicolato A, Foroni R, Reggio M, Gerosa M: Gamma knife radiosurgery for trigeminal neuralgia: results and potentially predictive parameters - part I: Idiopathic trigeminal neuralgia. Neurosurgery 61:1254 1261,2007

78. Lorenzoni J, David P, Levivier M: MR-based follow-up of the superior cerebellar artery after radiosurgery for trigeminal neuralgia. Clin Neurol Neurosurg 113:758-761, 2011

79. Love S, Coakham HB: Trigeminal neuralgia: pathology and pathogenesis. Brain 124:2347-2360, 2001

80. Lucas JT Jr, Nida AM, Isom S, Marshall K, Bourland JD, Laxton AW, et al: Predictive nomogram for the durability of pain relief from Gamma Knife radiation surgery in the treatment of trigeminal neuralgia. Int J Radiat Oncol Biol Phys 89:120-126, 2014

81. Ma L, Chin L, Sarfaraz M, Shepard D, Yu C: An investigation of eye lens dose for Gamma Knife treatments of trigeminal neuralgia. J Appl Clin Med Phys 1:116-119, 2000

82. Maesawa S, Salame C, Flickinger JC, Pirris S, Kondziolka D, Lunsford LD: Clinical outcomes after stereotactic radiosurgery for idiopathic trigeminal neuralgia. J Neurosurg 94:14-20, 2001

83. Marshall K, Chan MD, McCoy TP, Aubuchon AC, Bourland JD, McMullen KP, et al: Predictive variables for the successful treatment of trigeminal neuralgia with gamma knife radiosurgery. Neurosurgery 70:566-573, 2012

84. Massager N, Abeloos L, Devriendt D, Op de Beeck M, Levivier M: Clinical evaluation of targeting accuracy of gamma knife radio surgery in trigeminal neuralgia. Int $\mathbf{J}$ Radiat Oncol Biol Phys 69:1514-1520, 2007

85. Massager N, Lorenzoni J, Devriendt D, Desmedt F, Brotchi J, Levivier M: Gamma knife surgery for idiopathic trigeminal neuralgia performed using a far-anterior cisternal target and a high dose of radiation. J Neurosurg 100:597-605, 2004

86. Massager N, Murata N, Tamura M, Devriendt D, Levivier $\mathrm{M}$, Régis J: Influence of nerve radiation dose in the incidence of trigeminal dysfunction after trigeminal neuralgia radiosurgery. Neurosurgery 60:681-688, 2007

87. Massager N, Nissim O, Murata N, Devriendt D, Desmedt F, Vanderlinden B, et al: Effect of beam channel plugging on the outcome of gamma knife radiosurgery for trigeminal neuralgia. Int J Radiat Oncol Biol Phys 65:1200-1205, 2006

88. Matsuda S, Serizawa T, Nagano O, Ono J: Comparison of the results of 2 targeting methods in Gamma Knife surgery for trigeminal neuralgia. J Neurosurg 109 Suppl:185-189, 2008

89. Matsuda S, Serizawa T, Sato M, Ono J: Gamma knife radiosurgery for trigeminal neuralgia: the dry-eye complication. J Neurosurg 97 (5 Suppl):525-528, 2002

90. McNatt SA, Yu C, Giannotta SL, Zee CS, Apuzzo ML, Petrovich Z: Gamma knife radiosurgery for trigeminal neuralgia. Neurosurgery 56:1295-1303, 2005

91. Mousavi SH, Niranjan A, Huang MJ, Laghari FJ, Shin SS, 
Mindlin JL, et al: Early radiosurgery provides superior pain relief for trigeminal neuralgia patients. Neurology 85:2159_ 2165,2015

92. Nanda A, Javalkar V, Zhang S, Ahmed O: Long term efficacy and patient satisfaction of microvascular decompression and gamma knife radiosurgery for trigeminal neuralgia. $\mathbf{J}$ Clin Neurosci 22:818-822, 2015

93. North RB, Kidd DH, Piantadosi S, Carson BS: Percutaneous retrogasserian glycerol rhizotomy. Predictors of success and failure in treatment of trigeminal neuralgia. J Neurosurg 72:851-856, 1990

94. Oh IH, Choi SK, Park BJ, Kim TS, Rhee BA, Lim YJ: The treatment outcome of elderly patients with idiopathic trigeminal neuralgia: micro-vascular decompression versus Gamma knife radiosurgery. J Korean Neurosurg Soc 44:199-204, 2008

95. Pan HC, Sheehan J, Huang CF, Sheu ML, Yang DY, Chiu WT: Quality-of-life outcomes after Gamma Knife surgery for trigeminal neuralgia. J Neurosurg 113 Suppl:191-198, 2010

96. Park KJ, Kano H, Berkowitz O, Awan NR, Flickinger JC, Lunsford LD, et al: Computed tomography-guided gamma knife stereotactic radiosurgery for trigeminal neuralgia. Acta Neurochir (Wien) 153:1601-1609, 2011

97. Park KJ, Kondziolka D, Kano H, Berkowitz O, Ahmed SF, Liu X, et al: Outcomes of Gamma Knife surgery for trigeminal neuralgia secondary to vertebrobasilar ectasia. J Neurosurg 116:73-81, 2012

98. Park SH, Hwang SK: Outcomes of gamma knife radiosurgery for trigeminal neuralgia after a minimum 3-year follow-up. J Clin Neurosci 18:645-648, 2011

99. Park SH, Hwang SK, Kang DH, Park J, Hwang JH, Sung JK: The retrogasserian zone versus dorsal root entry zone: comparison of two targeting techniques of gamma knife radiosurgery for trigeminal neuralgia. Acta Neurochir (Wien) 152:1165-1170, 2010

100. Park YS, Kim JP, Chang WS, Kim HY, Park YG, Chang JW: Gamma knife radiosurgery for idiopathic trigeminal neuralgia as primary vs. secondary treatment option. Clin Neurol Neurosurg 113:447-452, 2011

101. Parmar MK, Torri V, Stewart L: Extracting summary statistics to perform meta-analyses of the published literature for survival endpoints. Stat Med 17:2815-2834, 1998

102. Peddada AV, Sceats DJ, White GA, Bulz G, Gibbs GL, Switzer B, et al: CyberKnife radiosurgery for trigeminal neuralgia: unanticipated iatrogenic effect following successful treatment. J Neurosurg 115:940-944, 2011

103. Petit JH, Herman JM, Nagda S, DiBiase SJ, Chin LS: Radiosurgical treatment of trigeminal neuralgia: evaluating quality of life and treatment outcomes. Int J Radiat Oncol Biol Phys 56:1147-1153, 2003

104. Pollock BE: Comparison of posterior fossa exploration and stereotactic radiosurgery in patients with previously nonsurgically treated idiopathic trigeminal neuralgia. Neurosurg Focus 18(5):E6, 2005

105. Pollock BE, Ecker RD: A prospective cost-effectiveness study of trigeminal neuralgia surgery. Clin J Pain 21:317322, 2005

106. Pollock BE, Phuong LK, Gorman DA, Foote RL, Stafford SL: Stereotactic radiosurgery for idiopathic trigeminal neuralgia. J Neurosurg 97:347-353, 2002

107. Pollock BE, Schoeberl KA: Prospective comparison of posterior fossa exploration and stereotactic radiosurgery dorsal root entry zone target as primary surgery for patients with idiopathic trigeminal neuralgia. Neurosurgery 67:633-639, 2010

108. Pusztaszeri M, Villemure JG, Regli L, Do HP, Pica A: Radiosurgery for trigeminal neuralgia using a linear accelerator with BrainLab system: report on initial experience in Lausanne, Switzerland. Swiss Med Wkly 137:682-686, 2007
109. Rand RW, Jacques DB, Melbye RW, Copcutt BG, Levenick MN, Fisher MR: Leksell Gamma Knife treatment of tic douloureux. Stereotact Funct Neurosurg 61 (Suppl 1):93-102, 1993

110. Régis J, Carron R, Tuleasca C, Donnet A: Distal radiosurgical targeting for trigeminal neuralgia, in Sheehan J, Gerszten $\mathrm{P}$ (eds): Controversies in Stereotactic Radiosurgery: Best Evidence Recommendations. New York: Thieme, 2014, pp 120-130

111. Régis J, Manera L, Dufour H, Porcheron D, Sedan R, Peragut JC: Effects of the Gamma Knife trigeminal neuralgia. Stereotact Funct Neurosurg 64 (Suppl 1):182-192, 1995

112. Régis J, Metellus P, Hayashi M, Roussel P, Donnet A, BilleTurc F: Prospective controlled trial of gamma knife surgery for essential trigeminal neuralgia. J Neurosurg 104:913-924, 2006

113. Régis J, Tuleasca C: Fifteen years of Gamma Knife surgery for trigeminal neuralgia in the Journal of Neurosurgery: history of a revolution in functional neurosurgery. $\mathbf{J}$ Neurosurg 115 Suppl:2-7, 2011

114. Régis J, Tuleasca C, Resseguier N, Carron R, Donnet A, Gaudart J, et al: Long-term safety and efficacy of Gamma Knife surgery in classical trigeminal neuralgia: a 497-patient historical cohort study. J Neurosurg 124:1079-1087, 2016

115. Régis J, Tuleasca C, Resseguier N, Carron R, Donnet A, Yomo S, et al: The very long-term outcome of radiosurgery for classical trigeminal neuralgia. Stereotact Funct Neurosurg 94:24-32, 2016

116. Richards GM, Bradley KA, Tomé WA, Bentzen SM, Resnick DK, Mehta MP: Linear accelerator radiosurgery for trigeminal neuralgia. Neurosurgery 57:1193-1200, 2005

117. Riesenburger RI, Hwang SW, Schirmer CM, Zerris V, Wu JK, Mahn K, et al: Outcomes following single-treatment Gamma Knife surgery for trigeminal neuralgia with a minimum 3-year follow-up. J Neurosurg 112:766-771, 2010

118. Rogers CL, Shetter AG, Fiedler JA, Smith KA, Han PP, Speiser BL: Gamma Knife radiosurgery for trigeminal neuralgia: the initial experience of The Barrow Neurological Institute. Int J Radiat Oncol Biol Phys 47:1013-1019, 2000

119. Romanelli P, Heit G, Chang SD, Martin D, Pham C, Adler J: Cyberknife radiosurgery for trigeminal neuralgia. Stereotact Funct Neurosurg 81:105-109, 2003

120. Shaya M, Jawahar A, Caldito G, Sin A, Willis BK, Nanda A: Gamma knife radiosurgery for trigeminal neuralgia: a study of predictors of success, efficacy, safety, and outcome at LSUHSC. Surg Neurol 61:529-534, 2004

121. Sheehan J, Pan HC, Stroila M, Steiner L: Gamma knife surgery for trigeminal neuralgia: outcomes and prognostic factors. J Neurosurg 102:434-441, 2005

122. Sheehan JP, Ray DK, Monteith S, Yen CP, Lesnick J, Kersh $\mathrm{R}$, et al: Gamma Knife radiosurgery for trigeminal neuralgia: the impact of magnetic resonance imaging-detected vascular impingement of the affected nerve. J Neurosurg 113:53-58, 2010

123. Sivakanthan S, Van Gompel JJ, Alikhani P, van Loveren $\mathrm{H}$, Chen R, Agazzi S: Surgical management of trigeminal neuralgia: use and cost-effectiveness from an analysis of the Medicare Claims Database. Neurosurgery 75:220-226, 2014

124. Smith ZA, De Salles AA, Frighetto L, Goss B, Lee SP, Selch $\mathrm{M}$, et al: Dedicated linear accelerator radiosurgery for the treatment of trigeminal neuralgia. J Neurosurg 99:511-516, 2003

125. Smith ZA, Gorgulho AA, Bezrukiy N, McArthur D, Agazaryan N, Selch MT, et al: Dedicated linear accelerator radiosurgery for trigeminal neuralgia: a single-center experience in 179 patients with varied dose prescriptions and treatment plans. Int J Radiat Oncol Biol Phys 81:225-231, 2011

126. Soboleva OI, Golanov AV, Gorlachev GE, Galkin MV, Kadasheva AB, Antipina NA, et al: [CyberKnife stereotactic 
radiosurgery in the treatment of patients with trigeminal neuralgia.] Zh Vopr Neirokhir Im N N Burdenko 76:79-84, 2012

127. Somaza S, Hurtado W, Montilla E, Ghaleb J: Gamma knife radiosurgery to the trigeminal ganglion for treatment of trigeminal neuralgia secondary to vertebrobasilar ectasia. Surg Neurol Int 5 (Suppl 16):S580-S585, 2014

128. Szeifert GT, Salmon I, Lorenzoni J, Massager N, Levivier M: Pathological findings following trigeminal neuralgia radiosurgery. Prog Neurol Surg 20:244-248, 2007

129. Tang CT, Chang SD, Tseng KY, Liu MY, Ju DT: CyberKnife stereotactic radiosurgical rhizotomy for refractory trigeminal neuralgia. J Clin Neurosci 18:1449-1453, 2011

130. Tang X, Wu H, Wang B, Zhang N, Dong Y, Ding J, et al: A new classification and clinical results of Gamma Knife radiosurgery for cavernous sinus hemangiomas: a report of 53 cases. Acta Neurochir (Wien) 157:961-969, 2015

131. Tarricone R, Aguzzi G, Musi F, Fariselli L, Casasco A: Costeffectiveness analysis for trigeminal neuralgia: Cyberknife vs microvascular decompression. Neuropsychiatr Dis Treat 4:647-652, 2008

132. Tawk RG, Duffy-Fronckowiak M, Scott BE, Alberico RA, Diaz AZ, Podgorsak MB, et al: Stereotactic gamma knife surgery for trigeminal neuralgia: detailed analysis of treatment response. J Neurosurg 102:442-449, 2005

133. Tuleasca C, Carron R, Resseguier N, Donnet A, Roussel P, Gaudart J, et al: Decreased probability of initial pain cessation in classical trigeminal neuralgia treated with Gamma Knife surgery in case of previous microvascular decompression: a prospective series of 45 patients with $>1$ year of follow-up. Neurosurgery 77:87-95, 2015

134. Tuleasca C, Carron R, Resseguier N, Donnet A, Roussel P, Gaudart J, et al: Patterns of pain-free response in 497 cases of classic trigeminal neuralgia treated with Gamma Knife surgery and followed up for least 1 year. J Neurosurg 117 Suppl:181-188, 2012

135. Tuleasca C, Carron R, Resseguier N, Donnet A, Roussel P, Gaudart J, et al: Trigeminal neuralgia related to megadolichobasilar artery compression: a prospective series of twentynine patients treated with Gamma Knife surgery, with more than one year of follow-up. Stereotact Funct Neurosurg 92:170-177, 2014

136. Urgosik D, Liscak R, Novotny J Jr, Vymazal J, Vladyka V: Treatment of essential trigeminal neuralgia with gamma knife surgery. J Neurosurg 102 Suppl:29-33, 2005

137. Verheul JB, Hanssens PE, Lie ST, Leenstra S, Piersma H, Beute GN: Gamma Knife surgery for trigeminal neuralgia: a review of 450 consecutive cases. J Neurosurg 113 Suppl:160-167, 2010

138. Villavicencio AT, Lim M, Burneikiene S, Romanelli P, Adler JR, McNeely L, et al: Cyberknife radiosurgery for trigeminal neuralgia treatment: a preliminary multicenter experience. Neurosurgery 62:647-655, 2008

139. Wiffen PJ, McQuay HJ, Moore RA: Carbamazepine for acute and chronic pain. Cochrane Database Syst Rev (3):CD005451, 2005

140. Worthington C, Hutson K, Boulware R, Neglia W, Gibbons JP, Clark R, et al: Computerized tomography cisternography of the trigeminal nerve for stereotactic radiosurgery. Case report. J Neurosurg 93 (Suppl 3): 169-171, 2000

141. Xu Z, Schlesinger D, Moldovan K, Przybylowski C, Sun X, Lee CC, et al: Impact of target location on the response of trigeminal neuralgia to stereotactic radiosurgery. J Neurosurg 120:716-724, 2014

142. Xue J, Goldman HW, Grimm J, LaCouture T, Chen Y, Hughes L, et al: Dose-volume effects on brainstem dose tolerance in radiosurgery. J Neurosurg 117 Suppl:189-196, 2012
143. Yatshushiro K, Nakamura K, Tomosugi T, Fujimoto T, Kuratsu J: Cerebellar infarction with superior cerebellar artery occlusion after Gamma Knife radiosurgery for trigeminal neuralgia: case report, in 6th International Stereotactic Radiosurgery Society Congress. Marseille: ISRS, 2003 (Abstract)

144. Young B, Shivazad A, Kryscio RJ, St Clair W, Bush HM: Long-term outcome of high-dose Gamma Knife surgery in treatment of trigeminal neuralgia. J Neurosurg 119:11661175,2013

145. Young RF, Vermeulen SS, Grimm P, Blasko J, Posewitz A: Gamma Knife radiosurgery for treatment of trigeminal neuralgia: idiopathic and tumor related. Neurology 48:608-614, 1997

146. Zahra H, The BS, Paulino AC, Yoshor D, Trask T, Baskin $\mathrm{D}$, et al: Stereotactic radiosurgery for trigeminal neuralgia utilizing the BrainLAB Novalis system. Technol Cancer Res Treat 8:407-412, 2009

147. Zakrzewska JM, Lopez BC: Quality of reporting in evaluations of surgical treatment of trigeminal neuralgia: recommendations for future reports. Neurosurgery 53:110-122, 2003

148. Zhao ZF, Yang LZ, Jiang CL, Zheng YR, Zhang JW: Gamma Knife irradiation-induced histopathological changes in the trigeminal nerves of rhesus monkeys. J Neurosurg 113:39-44, 2010

149. Zheng LG, Xu DS, Kang CS, Zhang ZY, Li YH, Zhang $\mathrm{YP}$, et al: Stereotactic radiosurgery for primary trigeminal neuralgia using the Leksell Gamma unit. Stereotact Funct Neurosurg 76:29-35, 2001

\section{Disclaimer}

These guidelines should not be considered inclusive of all methods of care or exclusive of other methods of care reasonably directed to obtain similar results. Physicians must make the ultimate judgment on the basis of the characteristics and circumstances of each individual patient. Adherence to these guidelines will not ensure successful treatment in every situation. The authors of these guidelines and the International Stereotactic Radiosurgery Society assume no liability for the information, conclusions, or recommendations contained in this report.

\section{Disclosures}

Mr. Paddick has been a consultant for Elekta AB. Dr. Régis has been a consultant for Medtronic and has received support from Elekta for non-study-related clinical or research effort. Dr. Sahgal has received honoraria for past educational seminars from Medtronic, Elekta AB, Accuray Inc., and Varian Medical Systems and research grants from Elekta $\mathrm{AB}$ and belongs to the Elekta MR LINAC Research Consortium.

\section{Author Contributions}

Conception and design: Tuleasca, Régis, Sahgal, De Salles, Levivier. Acquisition of data: Tuleasca, Régis, Levivier. Analysis and interpretation of data: Tuleasca, Régis, Sahgal, Ma, MartínezÁlvarez, Paddick, Ryu, Slotman, Levivier. Drafting the article: Tuleasca. Critically revising the article: all authors. Reviewed submitted version of manuscript: all authors. Approved the final version of the manuscript on behalf of all authors: Tuleasca. Statistical analysis: Tuleasca, Levivier. Administrative/technical/material support: all authors. Study supervision: Régis, Sahgal, Levivier.

\section{Correspondence}

Constantin Tuleasca: Centre Hospitalier Universitaire Vaudois, Lausanne, Switzerland. email: constantin.tuleasca@gmail.com. 